\title{
The Epidermal Microbiome Within An Aggregation of Leopard Sharks (Triakis Semifasciata) Has Taxonomic Flexibility With Gene Functional Stability Across Three Time-Points
}

Michael Doane ( $\triangle$ michael.doane@flinders.edu.au )

Sydney Institute of Marine Science https://orcid.org/0000-0001-9820-2193

Colton Johnson

San Diego State University

Shaili Johri

Stanford University Hopkins Marine Station

Emma N. Kerr

San Diego State University

Megan M. Morris

Lawrence Livermore National Laboratory

Ric Desantiago

San Diego State University

Abigail C. Turnlund

University of Queensland - Saint Lucia Campus: The University of Queensland

Asha Goodman

San Diego State University

Maria Mora

San Diego State University

Laís Farias Oliveira Lima

San Diego State University

Andrew P. Nosal

University of California San Diego Scripps Institution of Oceanography

Elizabeth A. Dinsdale

Flinders University

\section{Research}

Keywords: Microbiome, leopard shark, Triakis semifasciata, shark skin, next-generation sequencing

Posted Date: September 15th, 2021 
DOl: https://doi.org/10.21203/rs.3.rs-850465/v1

License: (c) (1) This work is licensed under a Creative Commons Attribution 4.0 International License. Read Full License 
1 The epidermal microbiome within an aggregation of leopard sharks (Triakis semifasciata)

2 has taxonomic flexibility with gene functional stability across three time-points

3 Michael P. Doane ${ }^{1 \#}$, Colton Johnson ${ }^{2 \#}$, Shaili Johri ${ }^{3}$, Emma N. Kerr ${ }^{1}$, Megan M. Morris ${ }^{4}$, Ric

4 Desantiago $^{2}$, Abigail C. Turnlund ${ }^{5}$, Asha Goodman², Maria Mora ${ }^{2}$, Laís Farias Oliveira Lima ${ }^{2}$,

5 Andrew P. Nosal ${ }^{6,7}$, Elizabeth A. Dinsdale ${ }^{2}$

6

$7{ }^{1}$ College of Science and Engineering, Flinders University, Bedford Park, South Australia,

8 Australia

$9 \quad{ }^{2}$ Department of Biology, San Diego State University, San Diego, California, USA

$10{ }^{3}$ Hopkins Marine Station, Stanford University, Pacific Grove, California, USA

$11{ }^{4}$ Laurence Livermore National Labs, Livermore, California, USA

$12{ }^{5}$ Australian Centre for Ecogenomics, University of Queensland, St Lucia, Queensland, Australia

$13{ }^{6}$ Department of Environmental and Ocean Sciences, University of San Diego, San Diego,

14 California, USA

$15{ }^{7}$ Scripps Institution of Oceanography, University of California - San Diego, La Jolla, California, 16 USA

$17 \quad$ "co-first authors

Michael P. Doane: 0000-0001-9820-2193

20 michael.doane@flinders.edu.au

21 Colton Johnson: 0000-0001-8895-6813

22 cjohnson1412@sdsu.edu

23 Shaili Johri: 0000-0001-7481-7548

24 shailij@stanford.edu

25 Emma N. Kerr

26 Emma.n.kerr@gmail.com

27 Megan M. Morris: 0000-0002-7024-8234

28 morris81@llnl.gov

29 Ricardo Desantiago

$30 \quad$ rdesantiago@sdsu.edu 
31 Abigail C. Turnlund

32 acturnlund@gmail.com

33 Asha Z. Goodman

34 azgoodman@sdsu.edu

35 Maria F. Mora

36 moramariaf21@gmail.com

37 Laís Farias Oliveira Lima: 0000-0002-7616-3637

38 laisfolima@gmail.com

39 Andrew P. Nosal: 0000-0002-1815-9269

40 anosal@ucsd.edu

41 Elizabeth A. Dinsdale: 0000-0002-2177-203X

42 elizabeth.dinsdale@flinders.edu.au

43

44

45

46

47

48

49

50

51

52

53

54

55

56

57

58 
The epidermal microbiome within an aggregation of Triakis semifasciata (leopard shark) has taxonomic flexibility with gene functional stability across three time-points Michael P. Doane ${ }^{1 \#}$, Colton Johnson ${ }^{2 \#}$, Shaili Johri ${ }^{3}$, Emma N. Kerr ${ }^{1}$, Megan M. Morris ${ }^{4}$, Ric Desantiago $^{2}$, Abigail C. Turnlund ${ }^{5}$, Asha Goodman ${ }^{2}$, Maria Mora $^{2}$, Laís Farias Oliveira Lima ${ }^{2}$, Andrew P. Nosal ${ }^{6,7}$, Elizabeth A. Dinsdale ${ }^{2}$

${ }^{1}$ College of Science and Engineering, Flinders University, Bedford Park, South Australia, Australia

$67{ }^{2}$ Department of Biology, San Diego State University, San Diego, California, USA

${ }^{3}$ Hopkins Marine Station, Stanford University, Pacific Grove, California, USA

${ }^{4}$ Laurence Livermore National Labs, Livermore, California, USA

${ }^{5}$ Australian Centre for Ecogenomics, University of Queensland, St Lucia, Queensland, Australia

${ }^{6}$ Department of Environmental and Ocean Sciences, University of San Diego, San Diego,

72 California, USA

${ }^{7}$ Scripps Institution of Oceanography, University of California - San Diego, La Jolla, California,

74 USA

\section{Abstract}

Background: The epidermis of Chondrichthyan fishes consists of dermal denticles with production of minimal but protein rich mucus that influence the attachment and biofilm development of microbes, facilitating a unique epidermal microbiome. Here, we use metagenomics to provide the taxonomic and functional characterization of the epidermal microbiome of the Triakis semifasciata (leopard shark) across three time-points to identify links between microbial groups and host metabolism. Our aims include 1) describing the variation of microbiome taxa over time and identify those members which are recurrent (present across all time-points, 2) investigating the relationship between the recurrent and flexible taxa (those which are not found consistently across time-points, 3) describing the functional compositions of the microbiome which may suggest links with the host metabolism; and 4) identifying whether the metabolisms are share across microbial genera or found in specific taxa.

Results: Microbial members of the microbiome showed high similarity between all individuals (average similarity: 82.74) with relative abundance of those members varying across years, suggesting flexibility of taxa in the microbiome. One hundred and eighty-eight genera were 
identified as recurrent, including Pseudomonas, Erythrobacter, Alcanivorax, Marinobacter and Sphingopxis being consistently abundance across time-points, while Limnobacter and Xyella exhibited switching patterns with high relative abundance in 2013, Sphingobium and Sphingomona in 2015, and Altermonas, Leeuwenhoekiella, Gramella and Maribacter in 2017. Of the 188 genera identified as recurrent, the top 19 relative abundant genera forming three recurrent groups. The microbiome also displayed high functional similarity between individuals (average similarity: 97.65) with gene function composition being consistent across time-points.

Conclusion: These results show that while presence of microbial genera exhibit consistency across time-points, their abundances do fluctuate. Functions however remain stable across time points; thus, we suggest the leopard shark microbiomes exhibit functional redundancy. We hypothesize this may be the result of the host's epidermal attributes structuring the microbiome. In addition, we show the co-existence of many microbial genera that carry genes which may enable the microbes to use the nutrients provided by the elasmobranch's metabolism.

Keywords: Microbiome, leopard shark, Triakis semifasciata, shark skin, next-generation sequencing

\section{Introduction}

The epidermis of marine organisms is biologically active (i.e. not keratinised like most terrestrial organisms)(Meyer and Seegers 2012), serving as the first line of defence against environmental influences. Along with providing broad protections, the skin of elasmobranchs interacts with the microbes from the surrounding environment, forming a specific microbiome (Doane et al., 2017). The epidermal microbiome of six elasmobranchs, including thresher sharks (Alopias vulpinus), whale sharks (Rhincodon typus), leopard sharks (Triakis semifasciata), blacktip reef sharks (Carcharhinus melanopterus), and round rays (Urobatis helleri) confirmed that the elasmobranch epidermal microbiomes are species-specific (Doane et al. 2017; Doane et al. 2020; Pogoreutz et al. 2019). However, the selection and maintenance of the microbiome on sharks remains an outstanding question, and may be the result of several processes, including 1) biophysical properties of the epidermis, 2) metabolism of the shark, and 3) interspecific interactions between the microbes. 
122 The biophysical properties of the chondrichthyan fish epidermis are uniquely covered with 123 dermal denticles that improve hydro-dynamism (Lang 2020). Dermal denticles have ridges and

124 troughs arranged in overlapping patterns that alter the hydrodynamic properties of water close to

125 the epidermis (Sullivan and Regan 2011b; Zhang et al. 2011; Wen et al. 2015) and this

126 biophysical property potentially affects microbial growth. In synthetic models mimicking shark

127 skin, two bacteria, Escherichia coli and Staphylococcus aureus, showed differential growth

128 patterns compared to a smooth surface. E. coli had high attachment rates to the structure surface,

129 whereas S. aureus was not able to attach (Chien et al. 2020), therefore, suggesting that only

130 specific types of microbes are able to attach to the shark skin. Further, modeling of microbial

131 community dynamics shows that high surface structural complexity can reduce competition

132 between microbes that result in chaotic spatial species distribution pattern on the surface

133 (Lowery and Ursell 2019). Therefore, the high micro-structured nature of the shark skin surface,

134 may produce similar dynamics in the microbiome. Further, the epidermis of Chondrichthyan fish

135 is characterized by a lower level of secretory cells compared with Actinopterygian fishes (Meyer

136 and Seeger 2012) and the product is a thin heterogeneous outer mucous layer (5-8 $\mu$ m thickness;

$137 \mathrm{pH}$ between 6 and 7). The mucus contains high levels of proteins, with only one protein being

138 identified, which is lectin pentraxin (Tsutsui et al. 2014) and has moderate to high disulphide

139 concentrations that is suspected to provide mechanical stabilization of the mucus coating (Meyer,

140 Seegers, and Stelzer 2007).

141

142 The metabolism of Elasmobranchs may also affect the functions of the microbiomes in the form

143 of secretions being transported by the skin mucus. Elasmobranchs rely on ketone bodies, fatty

144 acids, carbohydrates, and amino acids for energy production (Speers-Roesch and Treberg 2010).

145 Amino acids are ketogenic precursors, oxidative fuel, and nitrogen suppliers (Speers-Roesch and

146 Treberg 2010). Nitrogen metabolism is also important due to the high amount of urea

147 synthesised for osmoregulation, along with trimethylamine N-oxide (TMAO), which could also

148 be transported to the skin surface via mucus production (Ballantyne 1997; Speers-Roesch and

149 Treberg 2010). Sharks bioaccumulate toxins and heavy metals from lower trophic levels

150 (Escobar-Sanchez, Galvan-Magana, and Rosiles-Martinez 2010; Maz-Courrau et al. 2012) and

151 have been shown to exhibit maternal off-loading to their offspring in mucus surrounding 
152 developing embryo (Lyons and Lowe, 2013). Therefore, metabolic and harmful contaminants are

153 being leached from elasmobranchs in their mucus and if this occurs at the skin surface may

154 structure the skin microbiome. The microbiome signature from thresher sharks (Alopias

155 vulinpus) suggests potential heavy metal concentration at the skin interface signified by high

156 abundance of heavy metal resistance genes (Doane et al., 2017).

157

Interactions between the microbes on the surface and those from the surrounding water are also expected to affect the characteristics of the microbiome. The low levels of mucus secreted by the sharks and minimal biofilm development that occurred on the synthetic models of the shark skin, compared with the pronounced biofilm development on the smooth surface (Chien et al. 2020), suggests that microbial growth on the epidermis is suppressed, and the turnover of microbial communities may be high. Conversely, stability of a microbiome is important for the host's health and functioning, and rapid or unexpected variations in microbiome taxonomy leads to a state of dysbiosis, which can result in a decline in organismal health (Costello et al. 2012; Egan and Gardiner 2016). Therefore, an understanding of how the microbiome varies through time is important, but there are limited investigations of microbiome stability over time in the marine environment. A few examples include the epidermis microbiome of humpback whales (Megaptera novaeangliae) and Atlantic cod (Gadus morhua) which varied seasonally (Bierlich et al. 2018; Wilson, Danilowicz, and Meijer 2008), and similar seasonal changes occurred in the microbiome of the stony coral, Montastrea faveolata (Kimes et al. 2013). While the respiratory

172 microbiome of bottlenose dolphin species (Tursiops truncatus and Tursiops aduncus) maintained 173 taxonomic stability over two months, but individual dolphins had significantly different 174 microbiome taxonomic structures (Lima et al. 2012). In an analysis of 8 months, captive 175 dolphins had an individual signature of their lung microbiome and shared between $17-41 \%$ of the microbiome with other individuals (Vendl et al. 2021). In contrast, $77.6 \%$ of the microbes in

177 the epidermal microbiome of thresher sharks (A. vulpinus) were shared across individual sharks 178 (Doane et al. 2017), however, this study was only conducted at one timepoint. Therefore, 179 whether the epidermal microbiomes of marine vertebrate hosts are temporal stable or flexible 180 remains an outstanding question in science. 
182 Here we analyse both the taxonomic make-up and functional capabilities of the leopard shark

183 (Triakis semifasciata) epidermal microbiome over five years (three sampling time-points) using the following objectives: 1) to describe the variation of microbiome taxa over time and identify those members which are recurrent (present across time-points, 2) to investigate the relationship between the recurrent and flexible taxa (those which are not found consistently across timepoints, 3) to describe the functional compositions of the microbiome which may suggest links with the host metabolism; and 4) to identify whether the metabolisms are share across microbial genera or found in specific taxa.

\section{Materials and Methods}

Epidermal Microbiome Sampling

Leopard sharks (Triakis Semifasciata) sharks form consistent aggregations in late summer, early fall at near-shore locations (Nosal et al. 2014; Nosal et al. 2013) along the coast of California making this species a good candidate to investigate temporal microbiome dynamics of a wild animal. Sharks in this study were sampled from La Jolla Cove, California, USA (3251'12” N, $\left.117^{\circ} 15^{\prime} 48^{\prime \prime} \mathrm{W}\right)$. We targeted at least three sharks per year, and captured eight sharks in 2013 , three in 2015 , and seven in 2017 , thus the study was conducted over a five-year period. The sharks were caught with a handline on baited barbless circle hooks and brought onboard a small skiff for processing using a scoop net; all sharks were released after processing. Microbiome samples from the sharks were collected using a microbial collection tool, which flushes the epidermis with $\sim 250 \mathrm{ml}$ of sterile seawater and dislodges the microbes. The microbial slurry is collected into the back end of the microbial tool, as we have conducted previously (Doane et al. 2017; Doane et al. 2018; Doane et al. 2020; Johri et al. 2019; Lima et al. 2020). Each epidermal microbiome sample was taken from the flank region below the dorsal fin and above the lateral line. The collected microbiome samples were filtered through a $0.22 \mu \mathrm{m}$ Sterivex filter (Millipore, Inc.) and stored in a $-20^{\circ} \mathrm{C}$ freezer until processing.

\section{DNA Extraction and Sequencing}

Microbiome DNA was extracted using a cell lysis and spin-column filtration method by Macherey Nagel Tissue Kit. The purified DNA was prepared for random shot-gun sequencing using the standard protocol from Swift 2S Plus Kit (Swift Biosciences). The DNA library was 
213 sequenced using a Mi-Seq Illumina sequencer with Mi-Seq v3 Reagent Kit. Samples were bar-

214 coded and the $T$. semifasciata microbiomes were mixed in with a range of microbiome samples

215 and run on several sequencing runs.

216

217 Metagenome Annotation

218 The sequenced metagenomes were processed through PRINSEQ \pm \pm software for quality control, 219 removing sequences less than $70 \mathrm{bp}$, those that had a single $\mathrm{N}$, or a quality score below 25. MID 220 tags were also removed with PRINSEQ \pm \pm (Cantu, Sadural, and Edwards 2019; Schmieder and 221 Edwards 2011). The two fasta files were paired using FLASH software (Magoc and Salzberg 222 2011). After pairing, metagenomes were uploaded into MG-RAST Version 4.0.3, which was 223 used to provide taxonomic and functional gene annotations of the metagenomes using standard 224 cut-offs (Aziz et al. 2008; Meyer et al. 2008). The sequences with the highest bit score were 225 reported. The taxonomic annotation outputs were filtered in MG-RAST to only include those 226 from Bacteria and Archaea domains. Viruses and Eukaryotes were not used in the analysis

227 because they were underrepresented in the metagenome. The functional gene characterization 228 was obtained from the SEED platform (Overbeek et al. 2005), similar to previous analysis 229 (Dinsdale, Edwards, et al. 2008; Dinsdale, Pantos, et al. 2008).

\section{Quantitative evaluation of leopard shark microbiomes}

232 To identify whether the taxonomy of the microbiome remained consistent or varied over time, a 233 Permanova on the relative abundance of each taxon level was conducted across years (Anderson 234 2017). All data was fourth root transformed to reduce abundance variation among samples. A 235 simper analysis was used to identify the taxa contributing to the dissimilarity between years 236 (Clarke, Somerfield, and Gorley 2008). A principal coordinate analysis was performed on the 237 taxonomic data to visualize the variation in the structure of the microbiomes over the years. $\beta$ 238 diversity was identified using a Bray-Curtis analysis with 100 - similarity index, where $0=$ high 239 overlap, $100=$ no overlap. Last, a PERMDISP analysis compared the distribution of microbial 240 taxa across each year around the year's group centroid (Clarke, Somerfield, and Gorley 2016; 241 Anderson 2006). 
243 We identified a recurrent group of microbes (or core) as those genera that were present on every

244 individual shark, on a presence/absence basis and non-recurrent microbes, as all other genera that were an occasional member of the microbiome. The 19 most abundant recurrent and nonrecurrent microbial taxa (abundances calculated within the recurrent/non-recurrent datasets, separately) were compared with a Bray-Curtis similarity analysis to identified groups of genera that had a similar proportional abundance across years. A Pearson correlation was conducted to identify positive or negative correlations between these taxonomic groupings. The output of the Pearson correlation was organized into a heatmap and combined with the Bray-Curtis dendrogram. The analysis identified negative and positive correlations between the microbial groups that live on the shark epidermis.

To identify whether the functional potential of the shark epidermis microbiome remains stable or varies temporally, a PERMANOVA was conducted to compare variation in functional components across years. The SEED provides a hierarchal description including major metabolisms, metabolic pathways, gene clusters and gene functions (Overbeek et al. 2005). The SIMPER analysis identified potential functions that contributed to the dissimilarity between years. A principal coordinate analysis was performed to visualize the variation in the functional potential of the microbiomes over the years and a PERMDISP analysis compared the distribution of functional potential of $T$. semifasciata epidermal microbiome across years. All analyses were performed in PRIMER Version 6.1.15 \& PERMANOVA \pm Version 1.0.5 from PRIMER-E (2012). GraphPad Prism Version 8.3.1 was used to visualize the data.

We identified the functional potential of the 17 most proportionally abundant genera using the Krona plug-in (Ondov, Bergman, and Phillippy 2011) in MG-RAST (Aziz et al. 2008; Meyer et al. 2008). Only 17 genera were use because they occurred in sufficient abundance to explore the functions of the genera. The sequences were further investigated using Kyoto Encyclopedia of

273 sequences within the function across the 17 genera. The proportion of sequences associated with 
each function in each genus was categorized into one of four quartiles: $<75 \%, 50-75 \%, 25-$ $50 \%, 1-25 \%$, and $0 \%$ and visualized using a heatmap. The heatmap was used to visualize the connection between the microbes and the sharks over time and identified whether there was switching of specific functional roles between genera in the microbiome.

\section{Results}

\section{Temporal Taxonomy of the Epidermal Microbiome}

The epidermal microbiomes were constructed from 18 T. semifasciata, including seven individuals in 2013, three in 2015 and eight in 2017 caught in La Jolla, California. Metagenomes ranged from 312,135 - 2,347,886 sequences that had 89,080,935 - 605,042,370 base pairs (Table 1). Of those sequences identified as protein coding, $24.01-83.74 \%$ were classified as unknown sequences, which could not be matched to database (Table 1). The abundant phyla represented in the T. semifasciata epidermal microbiome were Proteobacteria $(78.50 \pm 2.02$ S.E. \%), Bacteroidetes $(15.83 \pm 2.34 \%)$, and Actinobacteria $(2.09 \pm 0.30 \%)$. Within the Proteobacteria the classes Gammaproteobacteria $(38.99 \pm 2.28 \%)$ and Alphaproteobacteria $(31.32 \pm 2.20 \%)$ were evenly represented, with Betaproteobacteria $(7.25 \pm 0.81 \%)$ and Deltaproteobacteria $(0.81$ $\pm 0.05 \%$ ) in lower relative abundance (SI Figure 1). Within the Bacteroidetes, the Flavobacteria class made up $12.08 \%( \pm 2.15)$ of the metagenome and Actinobacteria class accounted for 2.40 $\%( \pm 0.30)$ (SI Figure 2).

Across the 18 leopard sharks, 597 genera made up the epidermal microbiome. Highly represented genera present within the microbiomes included Pseudomonas $(9.85 \pm 1.81 \%)$, Erythrobacter (5.88 $\pm 0.69 \%)$, Leeuwenhoekiella (2.52 $\pm 0.72 \%)$, and Limnobacter (1.51 \pm 0.42 $\%$ ) (Figure 1). The T. semifasciata microbiomes collected across the three time-points showed high taxonomic similarity between all individuals, with average Bray-Curtis similarity of 82.74 $(0=$ no overlap, $100=$ total overlap $)$ among all pairs of samples. The similarity of the genera on the sharks across time-points suggests a selective process is occurring and that the shark epidermis has a specialized microbiome (Figure 1). The 19 most relative abundant genera (except for Providencia $2.29 \pm 0.94 \%$ ) were recurrent over sampling periods, but the proportional abundance varied throughout the years (Figure 3). The PERMANOVA analysis identified significant differences in the proportional abundances of all taxonomic levels between years (PERMANOVA: Phylum, Pseudo-F $\mathrm{F}_{\mathrm{df}}=2=3.696, \mathrm{P}($ perm $)=0.001 ;$ Class, Pseudo- $\mathrm{F}_{\mathrm{df}}=2=$ 
3.628, $\mathrm{P}($ perm $)=0.001$; Order, Pseudo- $\mathrm{F}_{\mathrm{df}=2}=3.222, \mathrm{P}($ perm $)<0.01 ;$ Family, Pseudo- $\mathrm{F}_{\mathrm{df}}=2=$ $2.762, \mathrm{P}($ perm $)<0.01$; Genus, Pseudo- $\mathrm{F}_{\mathrm{df}}=2=2.967, \mathrm{P}($ perm $\left.)=0.049\right)$. The microbial genera of the $T$. semifasciata epidermal microbiomes formed distinct clusters for each year in the principal coordinate analysis, which explained $64.7 \%$ of the variation in the first two axes (Figure 2). A few outliers identified in 2013 and 2017 may be associated with variation in an individual shark's physiology, i.e., such as pregnancy.

The SIMPER analysis identified a similarity coefficient of 83.05 between $2013 \& 2015 ; 80.29$ for 2013 \& 2017; and 84.64 for $2015 \& 2017$ (Bray-Curtis similarity index, $100=$ similar, $0=$ no overlap). Genera of the Gammaproteobacteria class contributed the most to the dissimilarity between the years, followed by genera in the Alphaproteobacteria and Betaproteobacteria, and the Flavobacteria class from the Bacteroidetes phylum (Table 2). The variation in the relative abundance of Alcanivorax and Alteromonas contributed the most to the dissimilarity across years.

Last, we explored the variance within years of microbial taxonomy with PERMDISP analysis. Each year the microbiome showed a similar amount of variation within the microbiomes at each taxonomic level (PERMDISP: Phylum, $\mathrm{F}_{\mathrm{df}}=2,15=2.120, \mathrm{P}($ perm $)>0.1$; Class, $\mathrm{F}_{\mathrm{df}}=2,15=$ 2.439, $\mathrm{P}($ perm $)>0.1$; Order, $\mathrm{F}_{\mathrm{df}}=2,15=1.513, \mathrm{P}($ perm $)>0.5 ;$ Family, $\mathrm{F}_{\mathrm{df}}=2,15=2.019, \mathrm{P}($ perm $)$ $>0.1$; Genus, $\mathrm{F}_{\mathrm{df}}=2,15=2.142, \mathrm{P}($ perm $\left.)>0.05\right)$. The microbiomes from 2013, 2015, and 2017 showed a dispersion of $11.7( \pm 1.8), 6.0( \pm 0.8)$, and $10.1( \pm 1.3)$ respectively. In summary, the individual sharks shared many microbial genera suggesting a consistent taxon across the years, with flexibility in the proportional abundance.

\section{Temporally Recurrent Microbes}

Microbial genera present in all 18 metagenomes, were categorized as 'recurrent' which included 188 of 597 genera. The stability was considered further by comparing the proportional abundance of sequences within the 188 genera across sampling periods and identified a significant difference (PERMANOVA: Pseudo-F $\mathrm{df}=2,15=10.462, \mathrm{P}($ perm $)=0.001)$. The variability in the recurrent microbial genera, measured by PERMDISP (PERMDISP: $\mathrm{F}_{\mathrm{df}}=2,15=$ 0.029, $\mathrm{P}($ perm $)=0.983)$ indicated no difference across years with 2013, 2015, and 2017 showing a dispersion of $4.09( \pm 0.47), 4.07( \pm 0.57), 3.974( \pm 0.22)$, respectively. Collectively the 
fluctuations in the dominate genera along with similar variability across time suggest a flexible but regulated recurrent groups of microbes in the T. semifasciata microbiome.

\section{Relationship between recurrent and non-recurrent genera}

In the clustering analysis, the 19 dominant recurrent microbes formed three groups and the 19 non-recurrent microbes formed five separate groups (Figure 4). The recurrent group A consisted of Pseudomonas, Erythrobacter, Alcanivoriax, and Marinobacter, which showed an even proportional abundance across the five years and with Erythrobacter and Marinobacter having higher proportional abundance in 2013. The recurrent group B consisted of seven genera which showed higher proportional abundance in 2017 and included Leeuwenhoekiella, Altermonas, Gramella, Zunongwangia, Pseudoaltermonas, Flabacterium, and Maribacter. The recurrent group $\mathrm{C}$ consisted of six genera with lower proportional abundance, including Burkolderia, Novoshingobium and Sphingopyxis, which showed even distribution across the years, Rugeria, which showed proportional higher abundance in 2013 and 2017 and Sphingobium and Sphingomonas, which showed higher proportional abundance in 2015. The non-recurrent (top 19 most relative abundant genera not occurring across all sampling points) microbial group $\mathrm{A}$ consisted of three genera with lower proportional abundance in 2017, including Propionibacterium, Pirellula, and Plesiocystis. The non-recurrent microbial group B consisted of two genera that showed low but even proportional abundance across all years and included Aromatoleum and Chromobacterium. The non-recurrent microbial group $\mathrm{C}$ only consisted of Dokdonia, which displayed higher proportional abundance in 2017. The non-recurrent group D included Acidiphillium, Azorhizobium, Gluconobacter, and Sphingobacterium and the first two genera displayed low even proportional abundances throughout all years Gluconobacter and Sphingobium showed higher proportional abundance in 2017. The non-recurrent microbial group E, including Leadbetterella, Klebsiella, Neisseria, Oligotropha, Thauara, and Frankia. Leadbetterella displayed its highest proportional abundance in 2015. Klebsiella, Neisseria, and Thauara showed even proportional abundance across all years. Oligotropha and Frankia displayed lower proportional abundances at all years (Figure 4). There also occurred a clustering group termed 'mixed' because genera included those which were classified as both recurrent and non-recurrent including Endoritia, Limnobacter, Xylella, and Providencia genera. 
We then investigated the correlative relationship of recurrent and non-recurrent groups (Figure 4). The heatmap showed that Erythrobacter and Marinobacter (recurrent group A) were negatively correlated with all microbes in recurrent group B. Whereas Pseudomonas and Alcanivorax (recurrent group A) showed positive correlations with recurrent group B. Recurrent group A, however, was positivity correlated with non-recurrent group A and B. In contrast, recurrent group B was negatively correlated with non-recurrent group A and B but strongly associated with non-recurrent group C, Dokdonia. Recurrent group C was positively correlated with non-recurrent groups A, B, D, E, and the mixed group (Figure 4). These associations between taxa will be investigated further in the functional analysis to identify metabolisms that may drive the microbiome composition.

\section{Functional potential of the shark epidermis microbiome}

Annotated microbial sequences were categorized into 26 major metabolic groups, 153 metabolic pathways, 949 functional gene clusters, and 5,358 functional genes. The gene function profiles were highly stable across the three time-points as evidenced by the high functional similarity between individual sharks (mean 97.65, Bray-Curtis similarity index). There was not a significant difference between time-points in the functional potential of the microbiome (PERMANOVA: major metabolic groups, Psuedo-F $\mathrm{df}=2,15=1.8, \mathrm{P}($ perm) $>0.05$; metabolic pathways, Psuedo-F $\mathrm{df}=2,15=0.525, \mathrm{P}($ perm $)>0.5$; functional gene clusters, Pseudo- $\mathrm{F}$ df $=2,15=$ $1.182, \mathrm{P}($ perm $)>0.1)$. The similarity of the functional potential was shown by the single cluster on the principal coordinate analysis that explained $64.4 \%$ of the variation in the first two axes (Figure 5).

The major metabolic groups included carbohydrates (mean $10.96 \pm 0.32 \%$ ); amino acids \& derivatives $(9.17 \pm 0.19 \%)$; protein metabolism (7.88 $\pm 0.11 \%)$; and fatty acids, lipids, \& isoprenoids $(2.61 \pm 0.04 \%)$ (SI Figure 3). In nitrogen metabolism (1.23 $\pm 0.11 \%)$, there were 11 functional gene clusters in the microbiome including ammonia assimilation $(0.51 \pm 0.01 \%)$, nitrate and nitrite ammonification $(0.38 \pm 0.001 \%)$, and denitrification $(0.10 \pm 0.02 \%)$, but few sequences were associated with nitrogen fixing genes $(0.02 \pm 0.007 \%)$ suggesting high levels of organic nitrogen that are present on the shark. Urea decomposition $(0.27 \pm 0.02 \%)$ was present and there were a few sequences associated with trimethylamine N-oxide (TMAO) reductase $(0.004 \pm 0.001 \%)$. The functional gene clusters that perform fatty acid biosynthesis and 
metabolism are fatty acid biosynthesis FASII $(0.72 \pm 0.02 \%)$, fatty acid degradation regulons $(0.22 \pm 0.02 \%)$, and fatty acid metabolism $(0.13 \pm 0.01 \%)$. The functional gene clusters that complete protein biosynthesis and degradation are ATP dependent proteolysis in bacteria $(0.37 \pm$ $0.01 \%)$, bacterial proteasome $(0.30 \pm 0.02 \%)$, protein degradation $(0.20 \pm 0.01 \%)$, nucleolar protein complex $(1.01 \pm 0.05 \%)$, aminopeptidase $(0.18 \pm 0.01 \%)$, metallocarboxypeptidase $(0.04 \pm 0.006 \%)$, and bacterial ribosome LSU $(0.38 \pm 0.02 \%)$. A high proportional abundance of flagellar motility $(1.27 \pm 0.06 \%)$ and lower proportional abundance of bacterial chemotaxis $(0.36 \pm 0.02 \%)$ is consistent with low biofilm formation predicted on the shark epidermis. There was a high proportional abundance of functions associated with resistance to antibiotics and toxic compounds $(5.08 \pm 0.13 \%)$ and cobalt-zinc-cadmium resistance had a mean of $1.58 \pm 0.12$ $\%$, multidrug resistance efflux pumps $(0.85 \pm 0.05 \%)$, copper homeostasis $(0.69 \pm 0.05 \%)$, and the production of exopolysaccharide biosynthesis (EPS) $(0.058 \pm 0.008 \%)$ and Rhamnolipids produced by Pseudomonas $(0.005 \pm 0.002 \%)$ that are used in heavy metal detoxification, consistent with bioaccumulation of heavy metals and toxins by the large-bodied sharks.

\section{Microbial gene function across genera}

The 17 dominant recurrent genera were used to investigated whether functional genes were equally dispersed across the genera or confined to a small subset of microbes (Figure 6). Pseudomonas, had the highest proportion of sequences annotated to all metabolisms, including those involved in nitrate and nitrite ammonification and denitrification, and in association with Alcanivorax, also conducted ammonia assimilation. These two genera were positively correlated (Figure 6) with most other microbes, suggesting these were key functions in microbiome growth. In comparison, Marinobacter also specialized in these two functions plus urea decomposition and was negatively correlated Pseudomonas and Alcanivorax. Ruegeria and Novosphingobium were the only other genera that had a high proportion abundance of genes associated with urea decomposition, which may have caused the negatively correlated with recurrent group $\mathrm{B}$. The genera within recurrent group B had a high proportion of genes associated with carbon metabolism, with Gramella having a high proportion of genes within TCA cycle, Glycolysis and Serine cycle. Maribacter has a high proportion of genes in Glycolysis, Denitrification, and fatty acid biosynthesis. Many genera, including Pseudomonas, Alcanivorax, Erythrobacter, Leeuwenhoekiella, Altermonas, Gramella and Flavobacterium, had many sequences associated 
424 with protein biosynthesis and degradation, and fatty acid biosynthesis, which are associated with

425 the shark ketosis dominated metabolism. Genera within recurrent group C, including Ruegeria, 426 Sphingopyxis and Novosphingobium had a high proportion of genes associated with

427 Denitrification and fatty acid biosynthesis. All 17 genera, except 1, had sequences that matched

428 the copper, cobalt and cambium resistance and copper homoeostasis genes. The abundance of

429 these functions across most genera in the metagenomes suggests the important heavy metal

430 tolerance or manipulation for microbes living on the surface of sharks.

\section{Discussion}

433

The T. semifasciata epidermal microbiome was consistent between individual sharks with many genera shared across the three time-points spanning 5 years, one of the longest studies of marine vertebrate microbiomes to date. A recurrent set of 188 microbial genera were present on all individuals. However, there was flexibility in the proportional makeup of the microbiome across years, but the microbiome variability was consistent across years, suggesting similar ecological dynamics are occurring from year to year, despite some turnover in microbial genera. Regardless of the proportional abundance of each microbial genera, the functional potential was constant, suggesting that the epidermal microbes were responding to the unique environment of the $T$. semifasciata epidermis, including the dermal denticles that reduce biofilm build-up and potentially elements secreted via the minimal mucus associated with shark's metabolism.

\section{Leopard shark microbiome exhibits specificity and flexibility}

The T. semifasciata epidermal microbiome has a high relative abundance of Pseudomonas, Erythrobacter, Alcanivorax, and Marinobacter; whereas the thresher shark (Alopias vulpinus) epidermal microbiome had a high relative abundance of Pseudoalteromonas, Erythrobacter, Idiomarina, and Limnobacter (Doane et al. 2017); and the Carcharhinus melanopterus epidermal microbiome a high relative abundance of Psychrobacter, Pseudoalteromonas, Rhodobacter, and Alteromonas (Pogoreutz et al. 2019). While some genera were shared across shark species, the proportional abundance differed, suggesting that each elasmobranch microbiome has distinct characteristics which select for differing microbiome members. 
455 The highly shared microbiome across individual sharks within a timepoint and flexible communities across timepoints coupled with evidence that species microbiomes are distinct may be caused by the dermal denticles (Chien et al. 2020; Dillon, Norris, and O'Dea 2017) and metabolites secreted in the skin mucus as a result of the sharks metabolism. Dermal denticles alter the hydrodynamic properties of water close to the epidermis, reducing drag on the shark (Sullivan and Regan 2011a) and micro-organism growth (Wen et al. 2015; Zhang et al. 2011). A study that tested the recruitment of two lab microbial species found that only one species was able to successfully recruit, and biofilms did not develop (Chien et al. 2020; Kim et al. 2012). Biofilm development is dependent on quorum sensing, which is interrupted on rough surfaces (Kim et al. 2012). We showed that specific microbial taxa recruit to the epidermis of $T$. semifasciata and the proportion of motility genes are relatively high compared to the chemotaxis genes which are proportionally low in abundance in the leopard shark microbiomes. These features are consistent across the microbiome of four shark species (Doane et al. 2017; Doane et al. 2020).

Modelling of microbial community dynamics of surfaces with structural complexity, like the conditions on a sharkskin, potentially suggests there is lower interspecific competition, which results in a chaotic spatial distribution pattern of microbial species (Lowery and Ursell 2019). The $T$. semifasciata epidermal microbiome supports the modelling where 188 genera coexisted on all sharks across the three years, with flexibility in the relative abundance of those genera, suggesting that the epidermis may provide multiple niches for microbial taxa to survive. An emergent feature of the modelling is that competing genera do not go extinct (Lowery and Ursell 2019), and we show that many microbial species co-occurred on the sharkskin across the three time-points. The co-occurrence or positive correlations within the microbiome suggest niche partitioning and sharing of resources with several genera exhibiting abundance relationships (Figure 4). For example, Pseudomonas and Alcanivorax showed positive correlations with recurrent group B members, including Leeuwenhoekiella, Altermonas, Pseudoaltermonas, Flabacterium, and Maribacter, suggesting that these two genera could share resources. Erythrobacter and Marinobacter were negatively correlated with all microbes in recurrent group B, suggesting strong competition; this group was however positively correlated 
with non-recurrent group A and B, suggesting transient microbes add to the microbiome's growth at different years.

\section{Microbiome functional groups}

We then investigated the gene functions present in the groups of microbial genera that may explain the positive or negative relationships between genera in Figure 4. In addition, because host metabolism and microbial functions are linked (Lynch and Hsiao 2019), we identified functional genes in each genus that may be linked to the host metabolism and classify three broad functional groups, generalists (recurrent group A), opportunists (recurrent group B) and specialists (recurrent group C) based on the presence of potential genes in these microbial genera. The group A recurrent microbes are typical marine species that have highly flexible genomes and growth strategies, including heterotrophic and photo-heterotrophic growth. These organisms can utilize many of the nutrients that may be present on the shark epidermis or excreted in the mucus, including proteins, fatty acids and disulphides (Meyer and Seegers 2012). Pseudomonas, for example, had the highest relative abundance and are capable of mixotrophy and simultaneous use of sulphur, nitrogen, and carbon from the surrounds (Guo, Chen, and Lee 2019) and sequences similar to these genes were highly represented in the Pseudomonas in leopard shark microbiomes. Pseudomonas were positively correlation with many microbes (Figure 4), which may be enhanced by traits, such as phosphate solubilization, and ammonia production (Yang et al. 2019; Goswami et al. 2013). Several, Pseudomonas species poses urease activity (Goswami et al. 2015) and tolerate, transition metals via the production of extracellular polysaccharides (EPS), such as Rhamnolipids, that form complexes with heavy metals (Meliani 2015).

Alcanivorax species, a highly abundant recurrent group A microbe, reduced alkane

hydrocarbons, and possessed many enzymes for $\beta$-oxidation of fatty acids, the glyoxylate bypass, and the gluconeogenesis. These gene functions carried by Alcanivorax suggest they break down the complex hydrocarbons and fatty acid rich metabolites and may facilitate other member of the microbiome by providing simpler metabolic products that can be utilized. They also include enzymes for synthesis of riboflavin and unsaturated fatty acids and cardiolipin (Sabirova et al. 2020). Cardiolipin is a diphosphatidylglycerol lipid (Schlame, Brody, and Hostetler 1993) and is 
more highly saturated in sharks than other vertebrates (Shadwick, Farrell, and Brauner 2015) and sequences similar to Cardiolipin were identified in the metagenomes.

Erythrobacter species, a highly abundance group A microbe that was negatively correlated with many other microbes are mostly aerobic anoxygenic phototrophic bacteria, containing bacteriochlorophyll a, but lack the genes of autotrophic $\mathrm{CO}_{2}$ fixation pathway, thus photoheterotrophic metabolism requiring a supply of organic substrates. Several Erythrobacter species have genes encoding enzymes for glycolysis and the tricarboxylic acid cycle but lack genes for nitrogenase or nitrate reductase thus are reliant on other forms of organic nitrogen (Koblizek et al. 2003), which matches the lower proportion of sequences identified in the Erythrobacter in the T. semifasciata microbiome. Erythrobacter carry heavy metal resistance genes, including resistance to lead, cadmium, zinc, mercury, nickel, cobalt, and arsenicals (Zheng et al. 2016) and these genes were highly present in the metagenomic profiles. The behaviour of the leopard sharks, being in shallow water with higher light conditions may have provided the Erythrobacter with a competitive advantage over other microbial groups.

The last group A recurrent microbe was Marinobacter and these organisms are opportunistic generalists that switch rapidly between lithoheterotrophy to heterotrophy, in both anaerobic and aerobic conditions, in response to nutrient pulses. They have fast growth, outgrowing other species in culture (Handley and Lloyd 2013). Marinabacter are able to respire inorganic compounds that are usually found in metal rich environments (Handley and Lloyd 2013), and we show they have many genes associated with metal resistance and transport. Marinobacter use many hydrocarbons as a sole energy source, and produce large quantities of bioemulsifier, which aid in bacterial adhesion to hydrophobic surfaces.

The recurrent group B microbes, the opportunists, were negatively correlated with most other groups and had a high relative abundance of genes associated with carbon metabolism. Gramella species degrades high molecular weight organic matter and encoding hydrolytic enzymes predicting a preference for polymeric carbon sources and have range of gliding motility that provide for surface adhesion (Bauer et al. 2006), features that enable the organism to live on the surface of elasmobranchs. However, these microbes had fewer genes in ammonia assimilation, promoting their coexistence with the more abundant species. Leeuwenhoekiella, a marine Flavobacteria, has guiding motility, heterotrophic growth, is pigmented and often found in 
associated with photosynthetic microbes and converts nitroalkanes into nitrite (Tahon et al. 2020). Alteromonas are non-phototrophic, heterotrophic, with flexible genome for taking advantage of influx of nutrients, particularly polymers, and some degrade polycyclic aromatic hydrocarbons (Math et al. 2012). Alteromonas have high flexibility in the metal resistant genes and efflux pumps and show strain differences in the copper-zinc-colbalt gene (czc) cassettes by successive insertions at a tRNA gene, with the numbers of czc cassettes varying from zero to three (Lopez-Perez et al. 2012) and these highly abundant in this genus in the T. semifasciata microbiome. Pseudoalteromonas and Alteromonas utilized extracellular hydrolysis as the major decomposition pathway of peptides and released fragments of amino acids into the surrounding environment (Liu and Liu 2020) and may have enable them to outcompete Marinobacter which is unable to conduct extracellular hydrolysis processes. However, these free amino acids may be used by other microbes, such as the non-recurrent group C and D microbes.

The group $\mathrm{C}$ recurrent microbes, the specialists, had less relative abundance overall but showed high relative abundance of a few metabolic pathways (Figure 5). Ruegeria had a high proportion of sequences associated with urea metabolism, compared with its relatively low proportional abundance. Ruegeria are able to use Trimethylamine (TMA) and trimethylamine N-oxide (TMAO) as an energy source to product intracellular ATP (Lidbury, Murrell, and Chen 2015). TMAO and TMA are used by elasmobranchs for osmoregulation.

Sphingopyxis also had low relative abundance, utilizing carbon and nitrogen compounds as substrates for growth but are generally slow growing (Moran et al. 2007). Serine, a pathway that was overrepresented in Sphingopyxis, can serve as a nitrogen source for the growth of some species, but not as a carbon source (Williams et al. 2009). Ammonia and nitrate are used as nitrogen sources, but there is a high energetic cost associated with nitrate utilization (Verma et al. 2020). Sphingomonas are closely related to Sphingoyxis and both produces exopolysaccharides (EPS) (Chang et al. 2021). The production of these compounds may provide biofilm development on the shark skin. Therefore, each recurrent microbial group was providing a different set of functional genes that enhanced coexistence and reflected the products that may be associated with shark metabolism and excreted via the mucus.

\section{Gene functions linked to host metabolic processes}


575 The stability of the functional potential of the epidermal microbiome suggests the elasmobranch 576 physiology and dermal denticle topography are strong drivers of microbiome function, and we 577 have developed a model to link the microbiome function with shark metabolism (Figure 7).

578 Elasmobranchs rely on protein as the primary food source and use ketogenic pathways and

579

580

581

582

583

584

585

586

587

588

589

590

591

592

593

594

595

596

597

598

599

600

601

602

603

604

605 produce high ketone bodies and hydrocarbons (Speers-Roesch and Treberg 2010). The functions that were present in metagenomes suggests that the microbes were responding to the presence of these compounds in the minimal mucus that covers the sharks. For example, Alxavorax and Marinobacter carried the genes to degrade hydrocarbons. There are few descriptions of the compounds within the mucus of Elasmobranchs, and these included high levels of proteins (Tsutsui et al., 2009) with moderate to high disulphide concentrations (Meyer et al., 2007a). A recent transcriptome analysis of the integument of cookie cutter sharks identified Glyceraldehyde-3-phosphate dehydrogenase and Fructose-bisphosphate aldolase A transcripts, both play key roles in the glycolysis and gluconeogenesis (Delroisse et al. 2021) suggesting these products are being produced in the skin and may be available to the microbial community. Protein metabolism and nitrate and nitrite ammonification, urea decomposition with genes such as trimethylamine $\mathrm{N}$-oxide (TMAO) reductase were significant functions in the microbiomes. The low levels of nitrogen fixation in the microbiome and the high proportional abundance of nitrogen metabolism and urea decomposition and the presences of within the microbiome suggest the elasmobranch is a nitrogen-rich environment (Hazon et al. 2003; Dowd et al. 2010). Proteasomes, metallocarboxypeptidase, aminopeptidase genes, protein degradation and biosynthesis functional genes suggest a propensity of the microbes for protein degradation. There was no evidence of dentine, hydrolysate, or collagen degradation in the microbiome, suggesting that the microbes are not breaking down the dermal denticles, which signifies a lack of negative impact on the sharks. Therefore, a commensal connection between T. semifasciata and the epidermis microbiome is established through the passive resource subsidization of these microbiome functions.

Cobalt-zinc-cadmium resistance and ton/to transport genes are highly prevalent functional genes shared across epidermis microbiomes of T. semifasciata (this study), A. vulpinus (Doane et al. 2017), Rhincodon typus and Urobatis halleri (Doane et al. 2020). Elasmobranchs bioaccumulate heavy metals and shunt these compounds to the epidermis (Escobar-Sanchez, Galvan-Magana, 
606 and Rosiles-Martinez 2010; Maz-Courrau et al. 2012), and the epidermal microbiomes are 607 responding to the presence of these compounds. The prevalence of heavy metal resistance genes 608 may provide a biomarker of elasmobranchs health and identify those exposed to anthropogenic 609 sources of heavy metals in the environment providing an early warning sign of declining health. 610

\section{Conclusions}

612 The highly structured epidermis of elasmobranchs, in this case, T. semifasciata, promotes a 613 diverse microbiome that has a flexible taxonomic makeup where many genera coexist. The 614 microbial community was maintained by functional redundancy driven by the taxonomic 615 flexibility and various microbes "flip-flopping" in abundance with one another, which kept the 616 microbial niches filled across the years. The high relative abundance of genes involved in 617 nitrification and denitrification, urea decomposition, and heavy metal resistance genes in the 618 epidermis microbiome across all $T$. semifasciata individuals suggests a connection with the host 619 metabolism potentially through passive subsidization of organic nitrogen, proteins, 620 hydrocarbons, and heavy metals.

621 
622 Abbreviations

623 Not applicable

624

625 Ethical Approval and Consent to participate

626 Animal handling and ethics were reviewed at San Diego State University through IACUC under

627 permit APF \#14-05-011D, APF \#17-11-010D, APF \# 18-05-007D. Sampling was conducting

628 under state permit SCP \#12847 and SCP \#9893 from the California Department of Fish and

629 Wildlife.

630

631 Consent for publication

632 Not applicable

633

634 Availability of data and materials

635 All data will be publicly released upon publication.

636

637 Competing interests

638 The authors declare no conflict of interest.

639

$640 \quad$ Funding

641 We acknowledge support from S. Lo and B. Billings. We acknowledge funding support from

642 NSF Division of Undergraduate Education \# 1323809 and NSF Division of Molecular and

643 Cellular Science \# 1330800.

644

645 Author's contribution

646 MD collected all field samples, constructed the ideas and help write the paper, CJ analyzed the

647 data and wrote the manuscript, EK, AT, AG, SJ, captured and prepared samples and provide

648 feedback on the manuscript, MMM and LL provided sequencing and analysis, AN facilitated the

649 catching of leopard sharks, RD provided the illustration, ED conceptualized the idea, analyzed,

650 wrote and lead the project.

651

652 Acknowledgements 
653 We would like to thank the students in the SDSU undergraduate Ecological Metagenomic class 654 assisting with the processing and sequencing of the leopard shark metagenomes.

655

\section{Authors' information}

$657{ }^{1}$ College of Science and Engineering, Flinders University, Bedford Park, South Australia, 658 Australia; ${ }^{2}$ Department of Biology, San Diego State University, San Diego, California, USA;

$659{ }^{3}$ Hopkins Marine Station, Stanford University, Pacific Grove, California, USA; ${ }^{4}$ Laurence 660 Livermore National Labs, Livermore, California, USA; ${ }^{5}$ Australian Centre for Ecogenomics, 661 University of Queensland, St Lucia, Queensland, Australia; ${ }^{6}$ Department of Environmental and 662 Ocean Sciences, University of San Diego, San Diego, California, USA; ${ }^{7}$ Scripps Institution of 663 Oceanography, University of California - San Diego, La Jolla, California, USA 


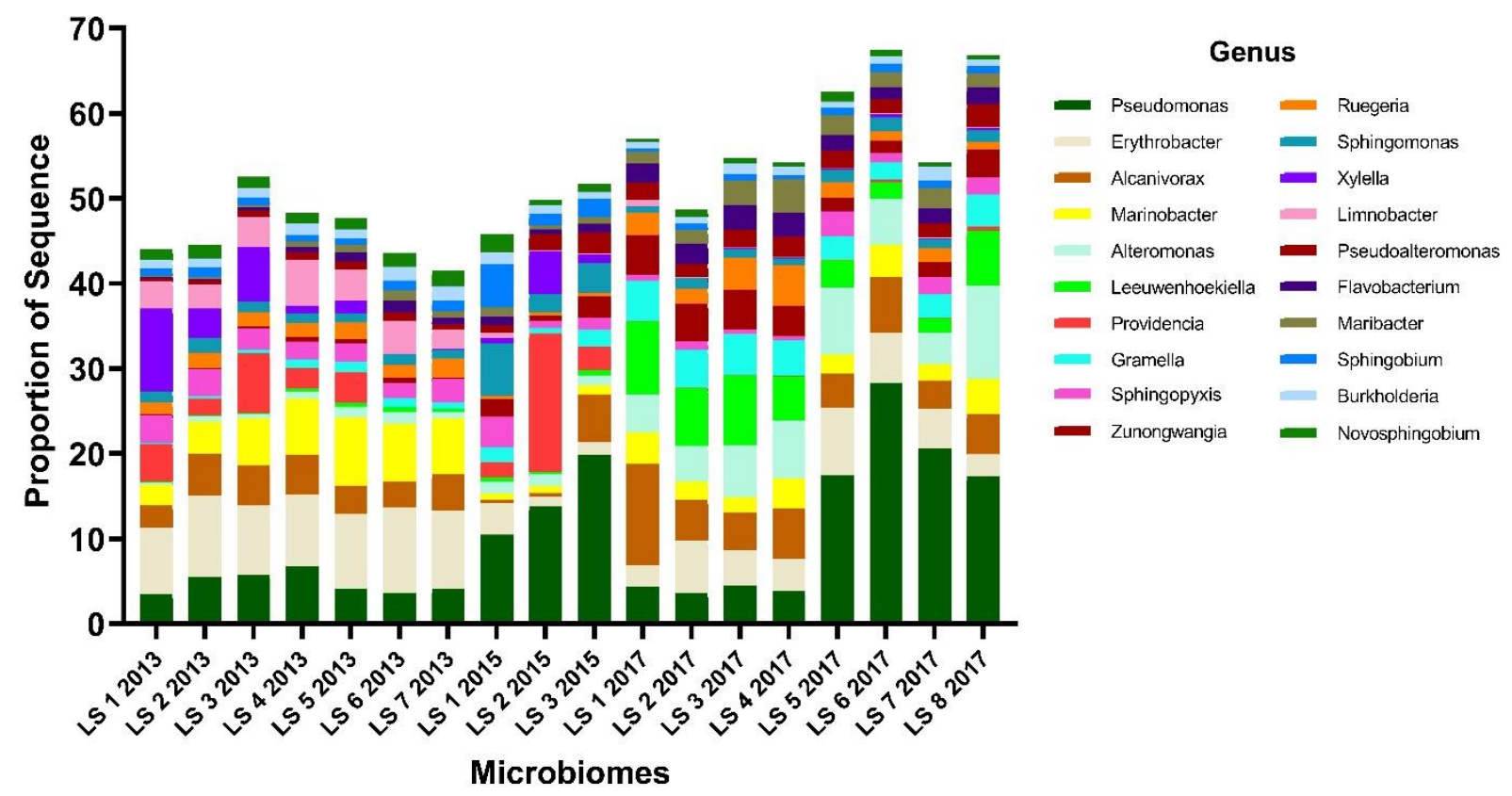

670 Figure 1. The relative proportions of the most abundant microbial genera represented in the Triakis 671 semifasciata microbiome across four years. 


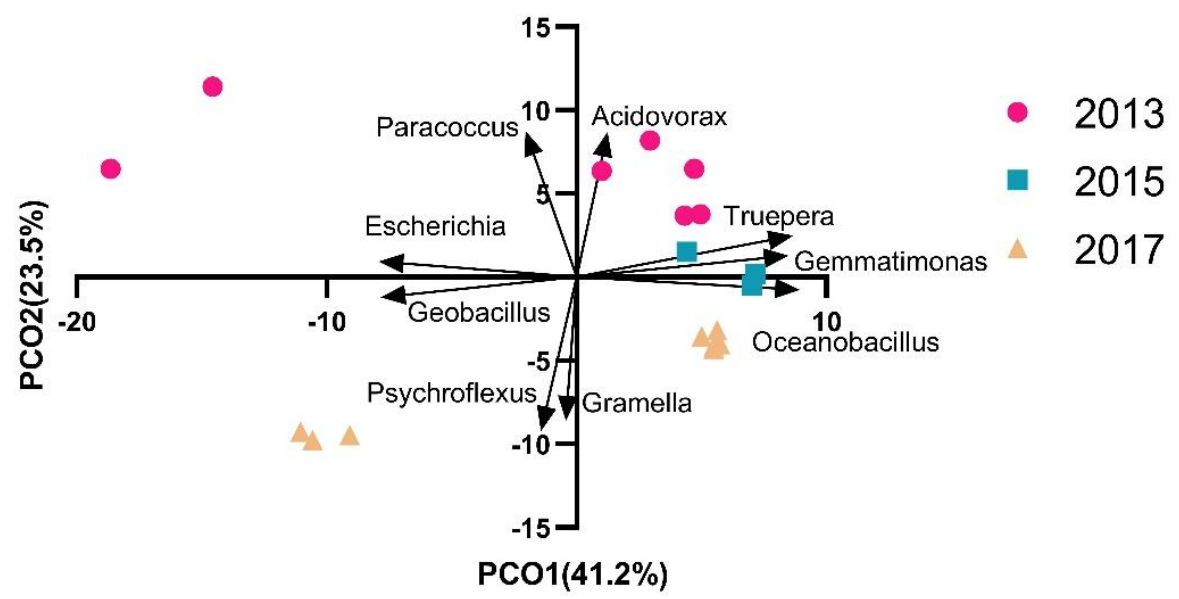

675

676 Figure 2 The microbial genera of the Triakis semifasciata epidermal microbiome clustered by year, with a 677 few outliers on the principal component analysis conducted on proportional sequence distribution. 


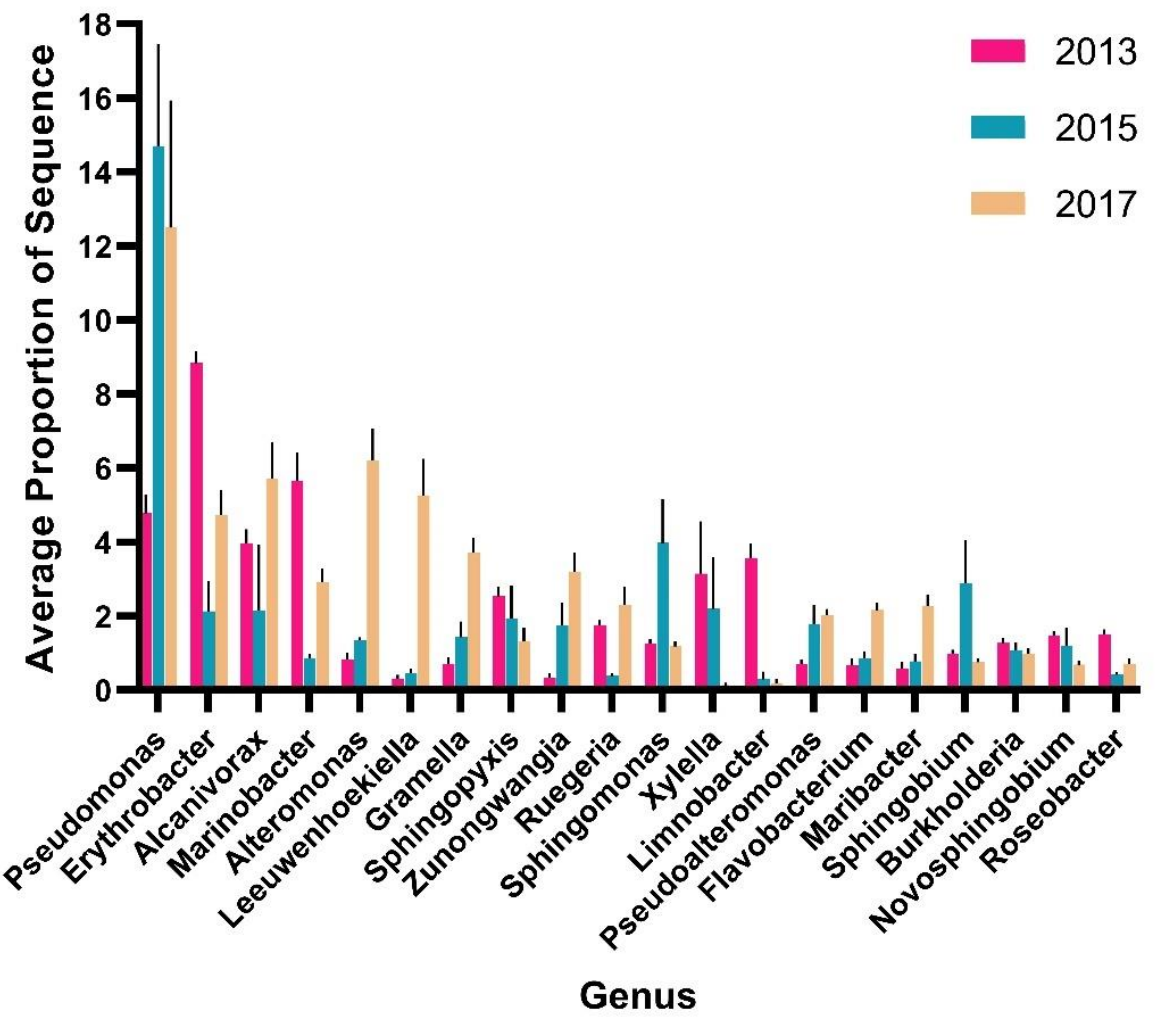

682 Figure 3. The mean relative abundance ( \pm S.E.) of abundant recurrent genera per year on the Triakis

683 semifasciata epidermal microbiome, showing flexibility with no abundant genera becoming extinct over 684 the four years. 


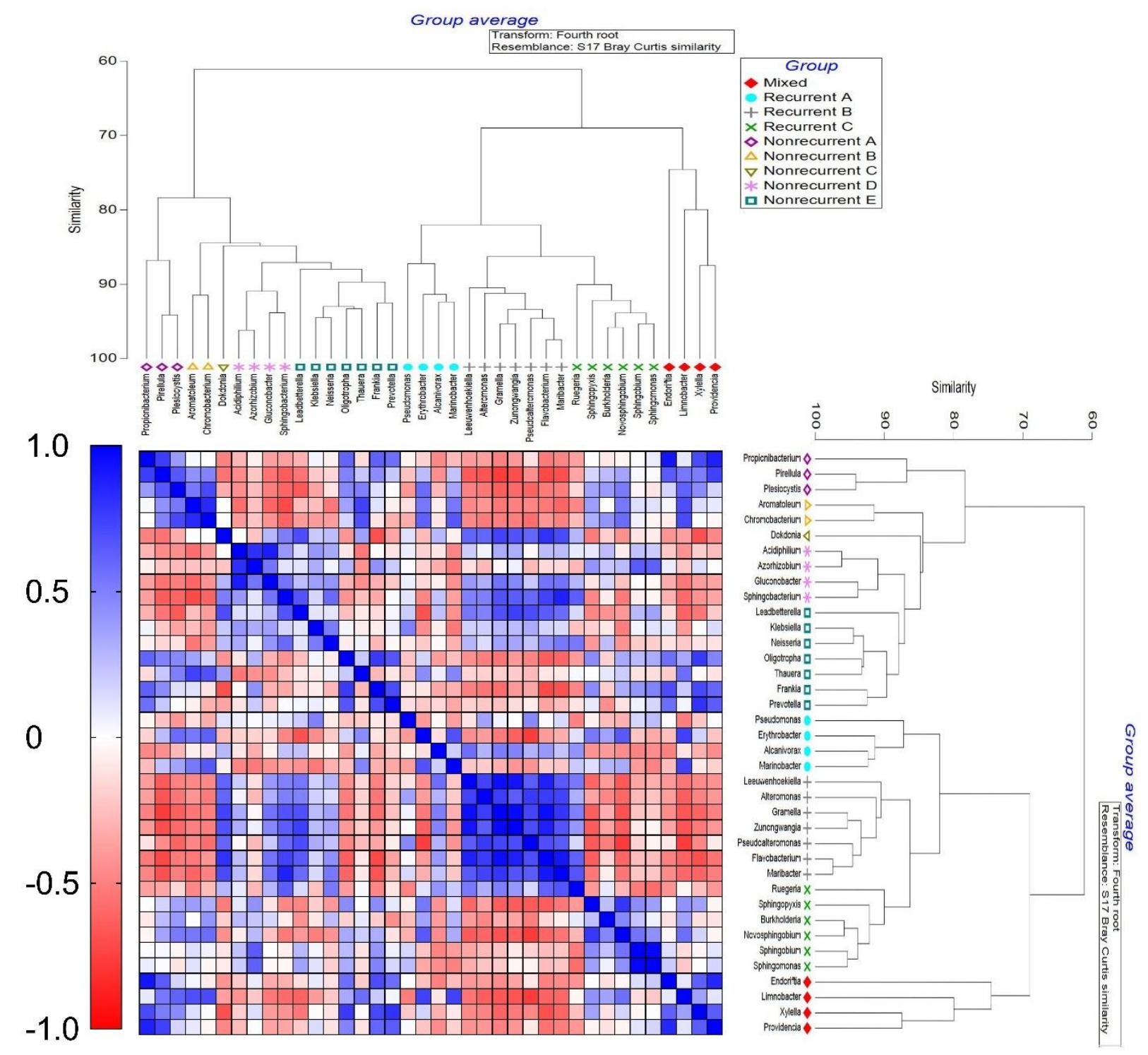

687 Figure 4. Positive and negative correlations occurred between most abundant 19 recurrent and non-

688 recurrent microbes in the Triakis semifasciata epidermal microbiome. Bray Curtis similarity was used to

689 cluster the genera with similar proportional abundance across years and the relationship with other genera

690 was compared using a Pearson's correlation, displayed as a heat map where red is a negative correlation

691 and blue is a positive correlation.

692

693 


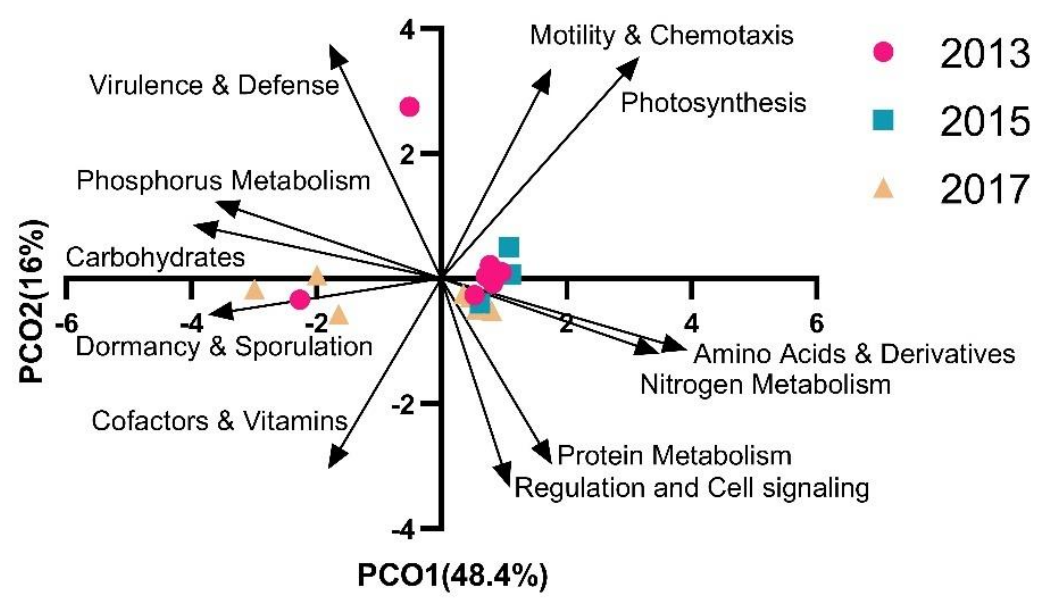

694

695

696 Figure 5. The functional potential of the Triakis semifasciata epidermal microbiome was stable across the 697 four-year period, shown using a principal component analysis.

698

699

700

701

702

703

704

705

706

707

708

709

710

711

712

713

714

715

716 


\begin{tabular}{|c|c|c|c|c|c|c|c|c|c|c|c|c|c|c|c|c|}
\hline \multirow[b]{2}{*}{ Function Group } & \multirow[b]{2}{*}{ Recurrent Genera } & \multicolumn{3}{|c|}{ Carbon Metabolism } & \multicolumn{4}{|c|}{ Nitrogen Metabolism } & \multicolumn{2}{|c|}{$\begin{array}{c}\text { Protein } \\
\text { Metabolism }\end{array}$} & \multicolumn{2}{|c|}{ Fatty Acids } & \multicolumn{2}{|c|}{ Heavy Metals } & \multicolumn{2}{|c|}{ Motility } \\
\hline & & 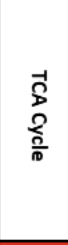 & 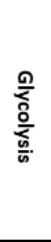 & 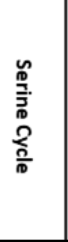 & 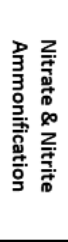 & 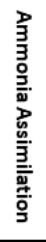 & 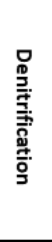 & 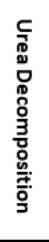 & 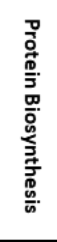 & 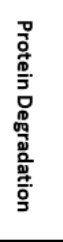 & 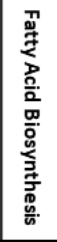 & 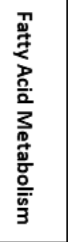 & 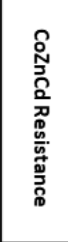 & 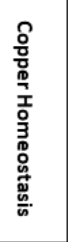 & 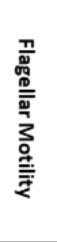 & 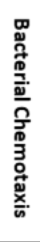 \\
\hline \multirow{4}{*}{ Generalist } & \begin{tabular}{|l|} 
Pseudomonas \\
\end{tabular} & & & & & & & & & & & & & & & \\
\hline & Alcanivorax & & & & & & & & & & & & & & & \\
\hline & Erythrobacter & & & & & & & & & & & & & & & \\
\hline & Marinobacter & & & & & & & & & & & & & & & \\
\hline \multirow{7}{*}{ Opportunist } & Leeuwenhoekiella & & & & & & & & & & & & & & & \\
\hline & Alteromonas & & & & & & & & & & & & & & & \\
\hline & Gramella & & & & & & & & & & & & & & & \\
\hline & Zunongwangia & & & & & & & & & & & & & & & \\
\hline & \begin{tabular}{|c|}
$\begin{array}{c}\text { Pseudoalteromon } \\
\text { as }\end{array}$ \\
\end{tabular} & & & & & & & & & & & & & & & \\
\hline & \begin{tabular}{|l|} 
Flavobacterium \\
\end{tabular} & & & & & & & & & & & & & & & \\
\hline & Maribacter & & & & & & & & & & & & & & & \\
\hline \multirow{6}{*}{ Specialist } & Ruegeria & & & & & & & & & & & & & & & \\
\hline & Sphingopyxis & & & & & & & & & & & & & & & \\
\hline & Burkholderia & & & & & & & & & & & & & & & \\
\hline & Novosphingobium & & & & & & & & & & & & & & & \\
\hline & Sphingobium & & & & & & & & & & & & & & & \\
\hline & Sphingomonas & & & & & & & & & & & & & & & \\
\hline
\end{tabular}

Figure 6. Heat map of the mean proportion of genes associated with each metabolism in the 17 most abundant recurrent taxon in group A (aqua), group B(grey) and group c (green), shows genes were mostly shared across taxon, but some specialization occurred. The proportion of sequences were divided into quartiles, where darker colors represent higher percentile (>75- dark red, 50-75 orange/red, 25-50 orange, and 0-25 - pale orange). No color represented no sequences for that metabolism held by that genus. 


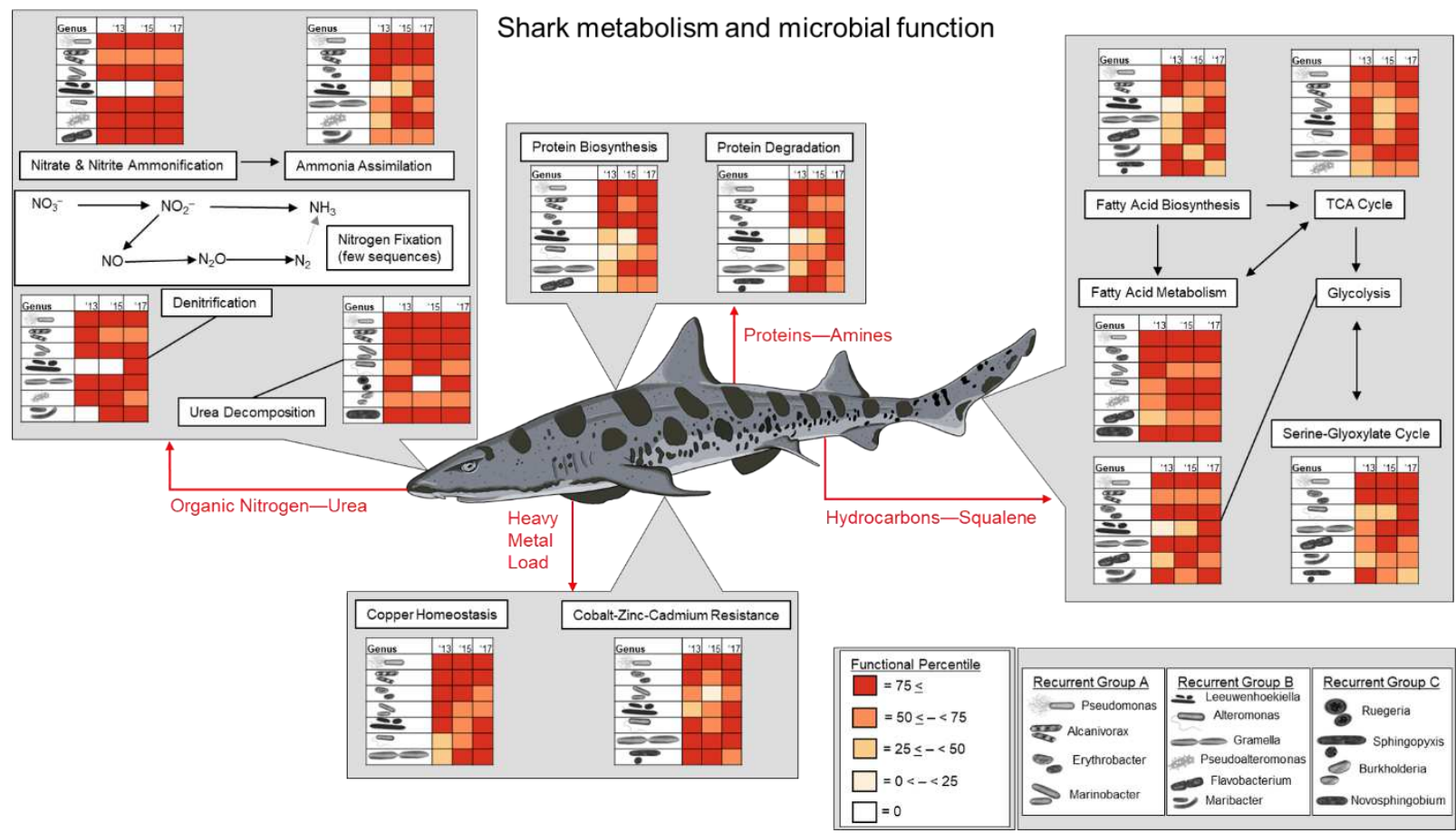

Figure 7. The links between the functional potential of the Triakis semifasciata epidermal microbiome

732 and the host metabolism. The proportion of each gene in each taxon were identified and classed into

733 quartiles. Most taxa had most functions suggesting the microbiome displays weak competition and is

734 responding to the metabolic processes of the host. 
741 Table 1. The Triakis semifasciata metagenome statistics, including collection date, total sequences and 742 proportion of the metagenome that was annotated by the database.

\begin{tabular}{|c|c|c|c|c|c|}
\hline $\begin{array}{l}\text { Metagenome } \\
\text { Name }\end{array}$ & Date & Location & SRA\# & $\begin{array}{l}\text { Number of } \\
\text { sequences }\end{array}$ & Annotated proteins (\%) \\
\hline LS 12013 & 2013 & La Jolla & & 1188249 & 20.69 \\
\hline LS 22013 & 2013 & La Jolla & & 1060680 & 24.36 \\
\hline LS 32013 & 2013 & La Jolla & & 1024296 & 20.16 \\
\hline LS 42013 & 2013 & La Jolla & & 1154296 & 21.33 \\
\hline LS 52013 & 2013 & La Jolla & & 2347886 & 19.79 \\
\hline LS 62013 & 2013 & La Jolla & & 3346424 & 18.84 \\
\hline LS 72013 & 2013 & La Jolla & & 2330953 & 20.36 \\
\hline LS 12015 & 2015 & La Jolla & & 1143301 & 22.68 \\
\hline LS 22015 & 2015 & La Jolla & & 2012275 & 15.87 \\
\hline LS 32015 & 2015 & La Jolla & & 1635251 & 20.4 \\
\hline LS 12017 & 2017 & La Jolla & & 701418 & 75.63 \\
\hline LS 22017 & 2017 & La Jolla & & 898767 & 74.86 \\
\hline LS 32017 & 2017 & La Jolla & & 636435 & 46.71 \\
\hline LS 42017 & 2017 & La Jolla & & 324102 & 68.57 \\
\hline LS 52017 & 2017 & La Jolla & & 312135 & 61.76 \\
\hline LS 62017 & 2017 & La Jolla & & 693318 & 43.43 \\
\hline Ls 72017 & 2017 & La Jolla & & 613946 & 62.52 \\
\hline LS 82017 & 2017 & La Jolla & & 1189453 & 43.69 \\
\hline
\end{tabular}


745 Table 2. The genera that contributed to the flexibility in the Triakis semifasciata epidermal

746 microbiome across four years, calculated via a Simper analysis, with dissimilarity coefficient of

$747 \quad 16.95$ between $2013 \& 2015$; 19.71 for $2013 \& 2017$; and 15.32 for $2015 \& 2017$

748

\begin{tabular}{|c|c|c|c|c|}
\hline $\begin{array}{l}\text { Years } \\
\text { compared }\end{array}$ & Phyla & Class & Genus & $\begin{array}{l}\text { Percent } \\
\text { Contribution }\end{array}$ \\
\hline \multirow[t]{10}{*}{2013 vs 2015} & Proteobacteria & Gammaproteobateria & Providencia & 0.9 \\
\hline & & & Endorifia & 0.86 \\
\hline & & & Marinobacter & 0.72 \\
\hline & & & Pseudomonas & 0.61 \\
\hline & & & xylella & 0.58 \\
\hline & & & Alcanivorax & 0.58 \\
\hline & & Betaproteobacteria & Liminobacter & 0.87 \\
\hline & & Alphaproteobacteria & Erythrobacter & 0.7 \\
\hline & & & Hyphomonas & 0.56 \\
\hline & & & Oceanibulbus & 0.66 \\
\hline \multirow[t]{10}{*}{2013 vs 2017} & Bacteroidetes & Flavobacteria & Leeuwenkoekiella & 0.9 \\
\hline & & & Zuongwangia & 0.7 \\
\hline & & & Gramella & 0.58 \\
\hline & Proteobacteria & Betaproteobacteria & Limnobacter & 0.89 \\
\hline & & Gammaproteobateria & Providencia & 0.89 \\
\hline & & & Alteromonas & 0.73 \\
\hline & & & Xylella & 0.67 \\
\hline & & & Endorifia & 0.54 \\
\hline & & Alphaproteobacteria & Hyphomonas & 0.48 \\
\hline & & Planctomycetia & Planctomyces & 0.47 \\
\hline \multirow[t]{10}{*}{2015 vs 2017} & Proteobacteria & Gammaproteobateria & Providencia & 1.41 \\
\hline & & & Endorifia & 1.11 \\
\hline & & & Psychrobacter & 0.91 \\
\hline & & & Xylella & 0.81 \\
\hline & & & Alcanivorax & 0.75 \\
\hline & & & Altermonas & 0.69 \\
\hline & & & Pseudomonas & 0.52 \\
\hline & & Alphaproteobacteria & Ruegeria & 0.59 \\
\hline & & Betaproteobacteria & Achromobacter & 0.56 \\
\hline & Bacteroidetes & Flavobacteria & Leeuwenkoekiella & 0.95 \\
\hline
\end{tabular}




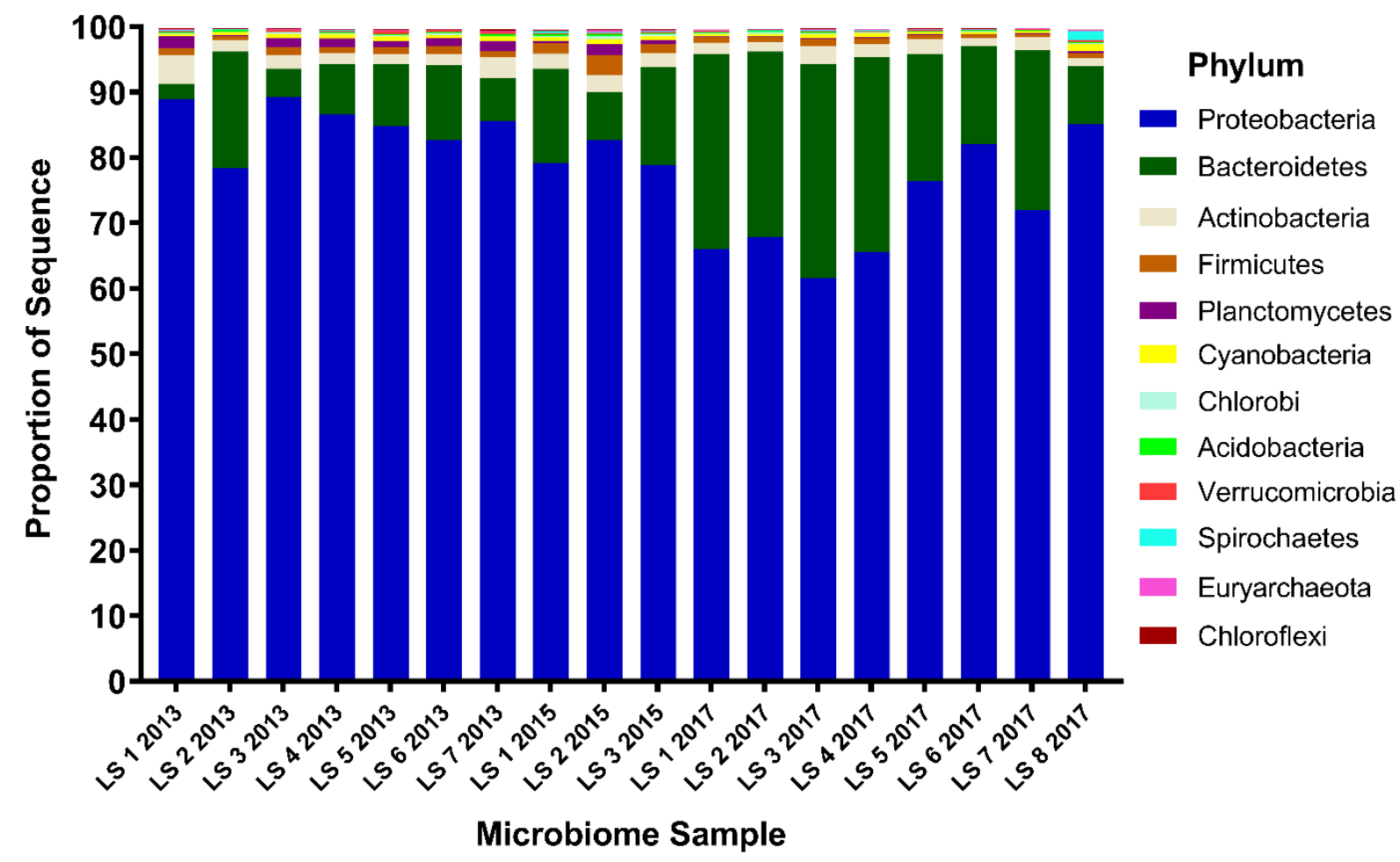

754 Supplementary Figure 1. The phylum profile of the Triakis semifasciata epidermal microbiome had 755 stable across four years. 


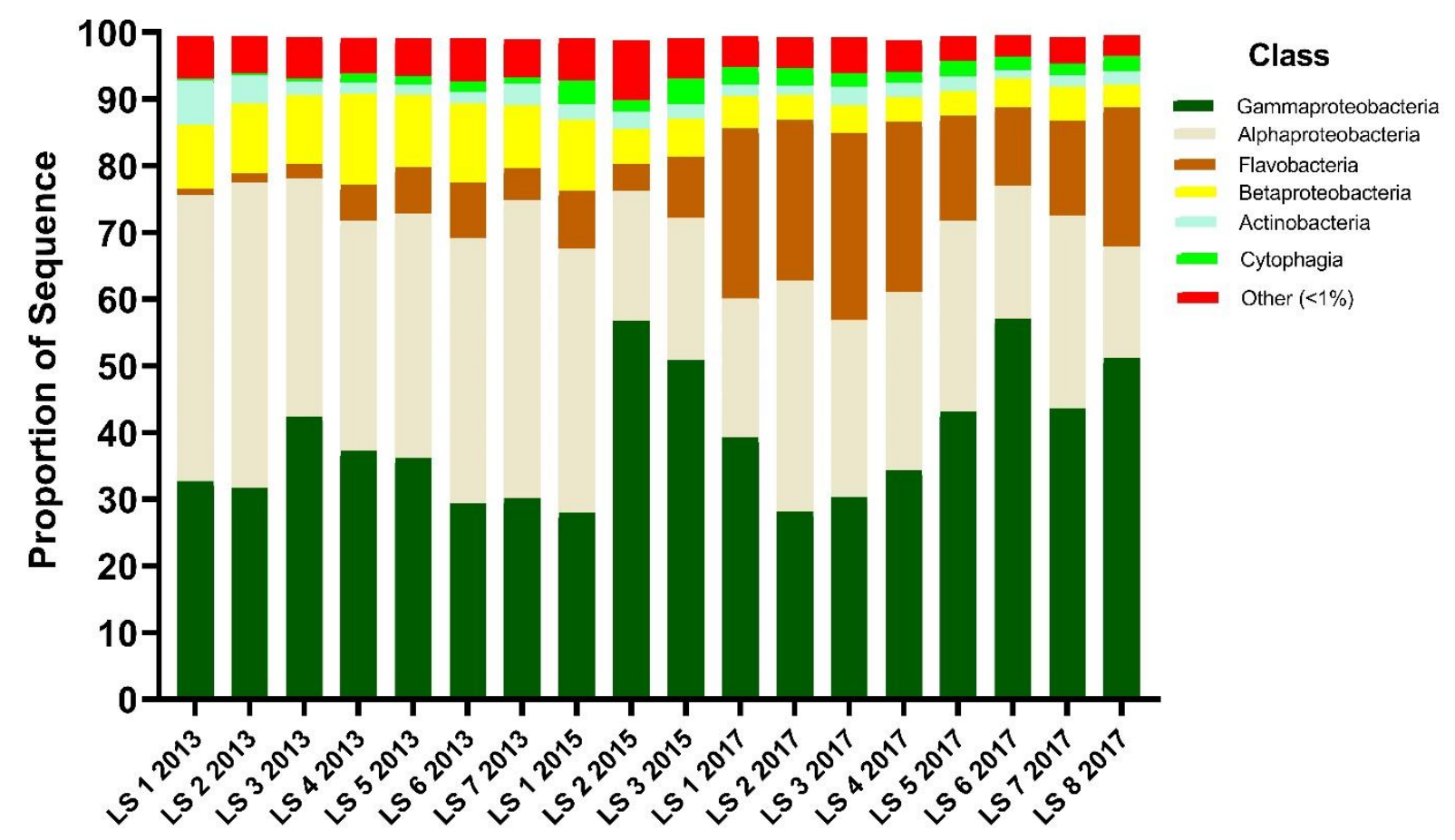

Microbiomes

758 Supplementary Figure 2.

759 The relative distribution of microbial classes in the Triakis semifasciata microbiome were similar over a 760 four-years. 


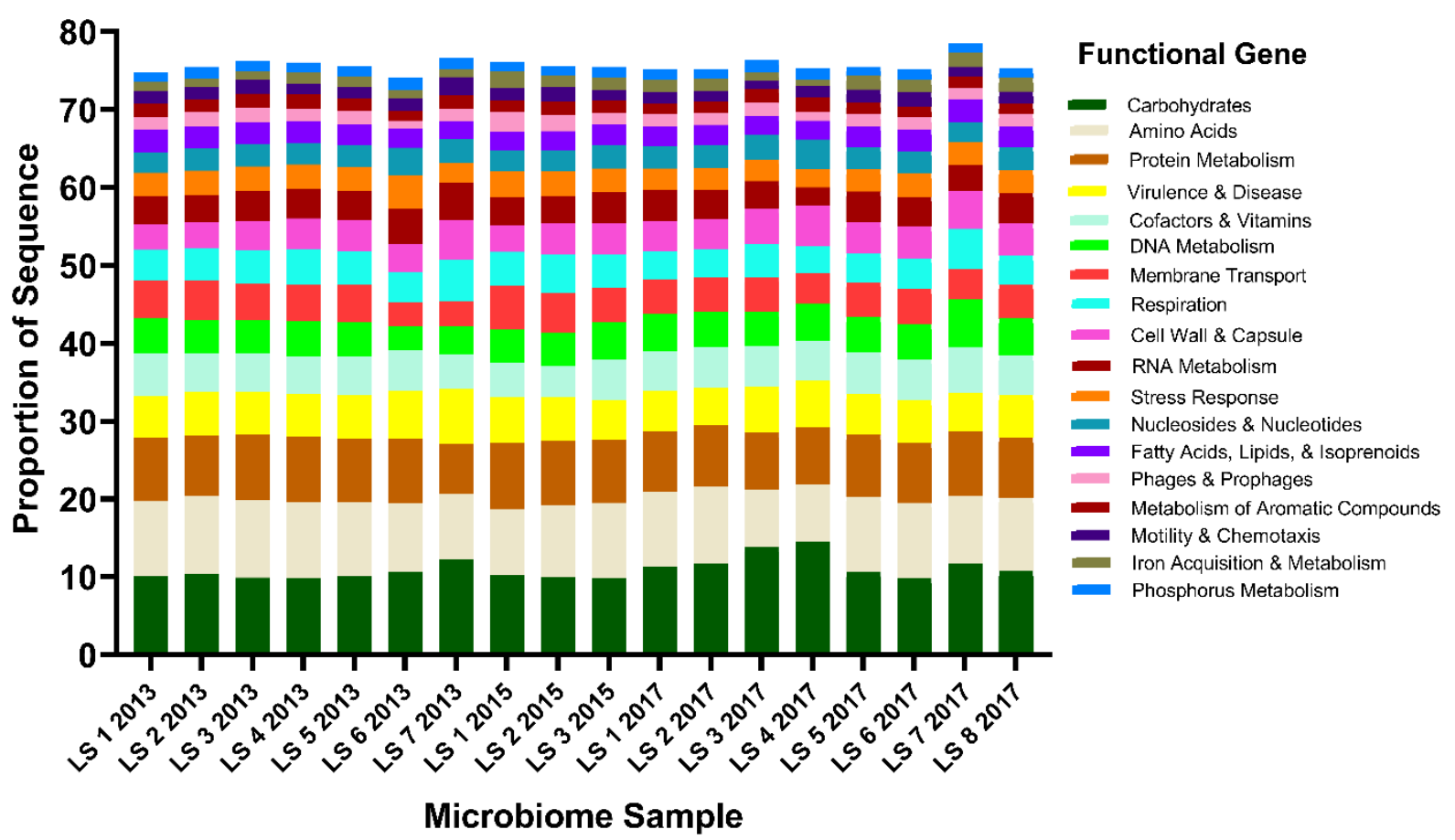

Supplementary Figure 3. The major metabolisms identifying within the Triakis semifasciata microbiomes.

\section{References}

Anderson, M. J. 2017. 'Permutational multivariate analysis of variance (PERMANOVA).' in T. Colton N. Balakrishnan, B. Everitt, W. Piegorsch, F. Ruggeri, and J. Teugels (ed.), Wiley statsref: statistics reference online (John Wiley and Sons: Hoboken, NJ, USA. ).

Anderson, M.J. 2006. 'Distance-based tests for homogeneity of multivariate dispersions. ', Biometrics,, 62: 245-53.

Aziz, R. K., D. Bartels, A. A. Best, M. DeJongh, T. Disz, R. A. Edwards, K. Formsma, S. Gerdes, E. M. Glass, M. Kubal, F. Meyer, G. J. Olsen, R. Olson, A. L. Osterman, R. A. Overbeek, L. K. McNeil, D. Paarmann, T. Paczian, B. Parrello, G. D. Pusch, C. Reich, R. Stevens, O. Vassieva, V. Vonstein, A. Wilke, and O. Zagnitko. 2008. 'The RAST server: Rapid annotations using subsystems technology', Bmc Genomics, 9.

Ballantyne, J. S. 1997. ' Jaws: the inside story. The metabolism of elasmobranch fishes. ', Comparative Biochemistry and Physiology Part B: Biochemistry and Molecular Biology . 118: 703-42.

Bauer, M., M. Kube, H. Teeling, M. Richter, T. Lombardot, E. Allers, C. A. Wurdemann, C. Quast, H. Kuhl, F. Knaust, D. Woebken, K. Bischof, M. Mussmann, J. V. Choudhuri, F. Meyer, R. Reinhardt, R. I. Amann, and F. O. Glockner. 2006. 'Whole genome analysis of the marine Bacteroidetes'Gramella forsetii' reveals adaptations to degradation of polymeric organic matter', Environmental Microbiology, 8: 2201-13.

Bierlich, K. C., C. Miller, E. DeForce, A. S. Friedlaender, D. W. Johnston, and A. Apprill. 2018. 'Temporal and Regional Variability in the Skin Microbiome of Humpback Whales along the Western Antarctic Peninsula', Appl Environ Microbiol, 84. 
Cantu, V. A., J. Sadural, and RA Edwards. 2019. 'PRINSEQ ++, a multi-threaded tool for fast and efficient quality control and preprocessing of sequencing datasets.', PeerJ Preprints, 7: 43-45.

Chang, A. P., J. Qian, H. Li, Y. L. Wang, J. Y. Lin, Q. M. He, Y. L. Shen, and H. Zhu. 2021. 'Characterization and Function of a Novel Welan Gum Lyase From Marine Sphingomonas sp. WG', Frontiers in Microbiology, 12: 638355.

Chien, H. W., X. Y. Chen, W. P. Tsai, and M. Lee. 2020. 'Inhibition of biofilm formation by rough shark skin-patterned surfaces', Colloids and Surfaces B-Biointerfaces, 186.

Clarke, K. R., P. J. Somerfield, and R. N. Gorley. 2008. 'Testing of null hypotheses in exploratory community analyses: similarity profiles and biota-environment linkage', Journal of Experimental Marine Biology and Ecology, 366: 56-69.

- - . 2016. 'Clustering in non-parametric multivariate analyses', Journal of Experimental Marine Biology and Ecology, 483: 147-55.

Costello, E. K., K. Stagaman, L. Dethlefsen, B. J. Bohannan, and D. A. Relman. 2012. 'The application of ecological theory toward an understanding of the human microbiome', Science, 336: 1255-62.

Delroisse, J., L. Duchatelet, P. Flammang, and J. Mallefet. 2021. 'Photophore Distribution and Enzymatic Diversity Within the Photogenic Integument of the Cookie-Cutter Shark Isistius brasiliensis (Chondrichthyes: Dalatiidae)', Frontiers in Marine Science, 8.

Dillon, E. M., R. D. Norris, and A. O'Dea. 2017. 'Dermal denticles as a tool to reconstruct shark communities', Marine Ecology Progress Series, 566: 117-34.

Dinsdale, E. A., R. A. Edwards, D. Hall, F. Angly, M. Breitbart, J. M. Brulc, M. Furlan, C. Desnues, M. Haynes, L. L. Li, L. McDaniel, M. A. Moran, K. E. Nelson, C. Nilsson, R. Olson, J. Paul, B. R. Brito, Y. J. Ruan, B. K. Swan, R. Stevens, D. L. Valentine, R. V. Thurber, L. Wegley, B. A. White, and F. Rohwer. 2008. 'Functional metagenomic profiling of nine biomes', Nature, 452: 629-U8.

Dinsdale, E. A., O. Pantos, S. Smriga, R. A. Edwards, F. Angly, L. Wegley, M. Hatay, D. Hall, E. Brown, M. Haynes, L. Krause, E. Sala, S. A. Sandin, R. V. Thurber, B. L. Willis, F. Azam, N. Knowlton, and F. Rohwer. 2008. 'Microbial ecology of four coral atolls in the Northern Line Islands', Plos One, 3 : e1584.

Doane, M. P., J. M. Haggerty, D. Kacev, B. Papudeshi, and E. A. Dinsdale. 2017. 'The skin microbiome of the common thresher shark (Alopias vulpinus) has low taxonomic and gene function -diversity', Environmental Microbiology Reports, 9: 357-73.

Doane, M. P., D. Kacev, S. Harrington, K. Levi, D. Pande, A. Vega, and E. A. Dinsdale. 2018. 'Mitochondrial recovery from shotgun metagenome sequencing enabling phylogenetic analysis of the common thresher shark (Alopias vulpinus)', Meta Gene, 15: 10-15.

Doane, M. P., M. M. Morris, B. Papudeshi, L. Allen, D. Pande, J. M. Haggerty, S. Johri, A. C. Turnlund, M. Peterson, D. Kacev, A. Nosal, D. Ramirez, K. Hovel, J. Ledbetter, A. Alker, J. Avalos, K. Baker, S. Bhide, E. Billings, S. Byrum, M. Clemens, A. J. Demery, L. F. O. Lima, O. Gomez, O. Gutierrez, S. Hinton, D. Kieu, A. Kim, R. Loaiza, A. Martinez, J. McGhee, K. Nguyen, S. Parlan, A. Pham, R. Price-Waldman, R. A. Edwards, and E. A. Dinsdale. 2020. 'The skin microbiome of elasmobranchs follows phylosymbiosis, but in teleost fishes, the microbiomes converge', Microbiome, 8.

Dowd, W. W., B. N. Harris, J. J. Cech, Jr., and D. Kultz. 2010. 'Proteomic and physiological responses of leopard sharks (Triakis semifasciata) to salinity change', Journal of Experimental Biology, 213: 210-24.

Egan, S., and M. Gardiner. 2016. 'Microbial Dysbiosis: Rethinking Disease in Marine Ecosystems', Frontiers in Microbiology, 7: 991.

Escobar-Sanchez, O., F. Galvan-Magana, and R. Rosiles-Martinez. 2010. 'Mercury and selenium bioaccumulation in the smooth hammerhead shark, Sphyrna zygaena Linnaeus, from the Mexican Pacific Ocean', Bull Environ Contam Toxicol, 84: 488-91. 
Goswami, D., K. Patel, S. Parmar, H. Vaghela, N Muley, P Dhandhukia, and J.N. Thakker. 2015. 'Elucidating multifaceted urease producing marine Pseudomonas aeruginosa BG as a cogent PGPR and bio-control agent.', Plant Growth Regulation, 75: 253-63.

Goswami, D., H. Vaghela, S. Parmar, P Dhandhukia, and J. Thakker. 2013. 'Plant growth promoting potentials of Pseudomonas spp. strain OG isolated from marine water.', J Plant Interact, 8: 28190.

Guo, H., C. Chen, and D. J. Lee. 2019. 'Nitrogen and sulfur metabolisms of Pseudomonas sp. C27 under mixotrophic growth condition', Bioresour Technol, 293: 122169.

Handley, K. M., and J. R. Lloyd. 2013. 'Biogeochemical implications of the ubiquitous colonization of marine habitats and redox gradients by Marinobacter species', Frontiers in Microbiology, 4.

Hazon, N., A. Wells, R. D. Pillans, J. P. Good, W. Gary Anderson, and C. E. Franklin. 2003. 'Urea based osmoregulation and endocrine control in elasmobranch fish with special reference to euryhalinity', Comp Biochem Physiol B Biochem Mol Biol, 136: 685-700.

Johri, S., M. P. Doane, L. Allen, and E. A. Dinsdale. 2019. 'Taking Advantage of the Genomics Revolution for Monitoring and Conservation of Chondrichthyan Populations', Diversity-Basel, 11.

Kanehisa, M., S. Goto, Y. Sato, M. Furumichi, and M. Tanabe. 2012. 'KEGG for integration and interpretation of large-scale molecular data sets', Nucleic Acids Research, 40: D109-D14.

Kanehisa, M., Y. Sato, M. Kawashima, M. Furumichi, and M. Tanabe. 2016. 'KEGG as a reference resource for gene and protein annotation', Nucleic Acids Research, 44: D457-D62.

Kim, M., S. Lee, H. D. Park, S. I. Choi, and S. Hong. 2012. 'Biofouling control by quorum sensing inhibition and its dependence on membrane surface', Water Science and Technology, 66: 1424-30.

Kimes, N. E., W. R. Johnson, M. Torralba, K. E. Nelson, E. Weil, and P. J. Morris. 2013. 'The Montastraea faveolata microbiome: ecological and temporal influences on a Caribbean reef-building coral in decline', Environmental Microbiology, 15: 2082-94.

Koblizek, M., O. Beja, R. R. Bidigare, S. Christensen, B. Benitez-Nelson, C. Vetriani, M. K. Kolber, P. G. Falkowski, and Z. S. Kolber. 2003. 'Isolation and characterization of Erythrobacter sp strains from the upper ocean', Archives of Microbiology, 180: 327-38.

Lang, Amy. 2020. 'The speedy secret of shark skin', Physics Today, 73: 58-59.

Lidbury, I. D., J. C. Murrell, and Y. Chen. 2015. 'Trimethylamine and trimethylamine N-oxide are supplementary energy sources for a marine heterotrophic bacterium: implications for marine carbon and nitrogen cycling', Isme Journal, 9: 760-9.

Lima, L. F. O., M. Weissman, M. Reed, B. Papudeshi, A. T. Alker, M. M. Morris, R. A. Edwards, S. J. de Putron, N. K. Vaidya, and E. A. Dinsdale. 2020. 'Modeling of the Coral Microbiome: the Influence of Temperature and Microbial Network', Mbio, 11.

Lima, N., T. Rogers, K. Acevedo-Whitehouse, and MV. Brown. 2012. 'Temporal stability and species specificity in bacteria associated with the bottlenose dolphins respiratory system.', Environ Microbiol Rep., 4: 89-96.

Liu, S., and Z. Liu. 2020. 'Distinct capabilities of different Gammaproteobacterial strains on utilizing small peptides in seawater', Sci Rep, 10: 464.

Lopez-Perez, M., A. Gonzaga, A. B. Martin-Cuadrado, O. Onyshchenko, A. Ghavidel, R. Ghai, and F. Rodriguez-Valera. 2012. 'Genomes of surface isolates of Alteromonas macleodii: the life of a widespread marine opportunistic copiotroph', Sci Rep, 2: 696.

Lowery, N. V., and T. Ursell. 2019. 'Structured environments fundamentally alter dynamics and stability of ecological communities', Proceedings of the National Academy of Sciences of the United States of America, 116: 379-88.

Lynch, J. B., and E. Y. Hsiao. 2019. 'Microbiomes as sources of emergent host phenotypes', Science, 365 : 1405-08. 
Magoc, T., and S. L. Salzberg. 2011. 'FLASH: fast length adjustment of short reads to improve genome assemblies', Bioinformatics, 27: 2957-63.

Math, R. K., H. M. Jin, J. M. Kim, Y. Hahn, W. Park, E. L. Madsen, and C. O. Jeon. 2012. 'Comparative genomics reveals adaptation by Alteromonas sp. SN2 to marine tidal-flat conditions: cold tolerance and aromatic hydrocarbon metabolism', Plos One, 7: e35784.

Maz-Courrau, A., C. Lopez-Vera, F. Galvan-Magana, O. Escobar-Sanchez, R. Rosiles-Martinez, and A. Sanjuan-Munoz. 2012. 'Bioaccumulation and biomagnification of total mercury in four exploited shark species in the Baja California Peninsula, Mexico', Bull Environ Contam Toxicol, 88: 129-34.

Meliani, A. 2015. 'Bioremediation Strategies Employed by Pseudomonas Species. .' in Maheshwari D. (ed.), Bacterial Metabolites in Sustainable Agroecosystem. Sustainable Development and Biodiversity (Springer,).

Meyer, F., D. Paarmann, M. D'Souza, R. Olson, E. M. Glass, M. Kubal, T. Paczian, A. Rodriguez, R. Stevens, A. Wilke, J. Wilkening, and R. A. Edwards. 2008. 'The metagenomics RAST server - a public resource for the automatic phylogenetic and functional analysis of metagenomes', $B M C$ Bioinformatics, 9.

Meyer, W., and U. Seegers. 2012. 'Basics of skin structure and function in elasmobranchs: a review', Journal of Fish Biology, 80: 1940-67.

Meyer, W., U. Seegers, and R. Stelzer. 2007. 'Sulphur, thiols, and disulphides in the fish epidermis, with remarks on keratinization', Journal of Fish Biology, 71: 1135-44.

Moran, M. A., R. Belas, M. A. Schell, J. M. Gonzalez, F. Sun, S. Sun, B. J. Binder, J. Edmonds, W. Ye, B. Orcutt, E. C. Howard, C. Meile, W. Palefsky, A. Goesmann, Q. Ren, I. Paulsen, L. E. Ulrich, L. S. Thompson, E. Saunders, and A. Buchan. 2007. 'Ecological genomics of marine Roseobacters', Appl Environ Microbiol, 73: 4559-69.

Nosal, A. P., A. Caillat, E. K. Kisfaludy, M. A. Royer, and N. C. Wegner. 2014. 'Aggregation behavior and seasonal philopatry in male and female leopard sharks Triakis semifasciata along the open coast of southern California, USA', Marine Ecology Progress Series, 499: 157-75.

Nosal, A. P., D. C. Cartamil, J. W. Long, M. Luhrmann, N. C. Wegner, and J. B. Graham. 2013. 'Demography and movement patterns of leopard sharks (Triakis semifasciata) aggregating near the head of a submarine canyon along the open coast of southern California, USA', Environmental Biology of Fishes, 96: 865-78.

Ondov, B. D., N. H. Bergman, and A. M. Phillippy. 2011. 'Interactive metagenomic visualization in a Web browser', BMC Bioinformatics, 12: 385.

Overbeek, R., T. Begley, R. M. Butler, J. V. Choudhuri, H. Y. Chuang, M. Cohoon, V. de Crecy-Lagard, N. Diaz, T. Disz, R. Edwards, M. Fonstein, E. D. Frank, S. Gerdes, E. M. Glass, A. Goesmann, A. Hanson, D. Iwata-Reuyl, R. Jensen, N. Jamshidi, L. Krause, M. Kubal, N. Larsen, B. Linke, A. C. McHardy, F. Meyer, H. Neuweger, G. Olsen, R. Olson, A. Osterman, V. Portnoy, G. D. Pusch, D. A. Rodionov, C. Ruckert, J. Steiner, R. Stevens, I. Thiele, O. Vassieva, Y. Ye, O. Zagnitko, and V. Vonstein. 2005. 'The subsystems approach to genome annotation and its use in the project to annotate 1000 genomes', Nucleic Acids Research, 33: 5691-702.

Pogoreutz, C., M. A. Gore, G. Perna, C. Millar, R. Nestler, R. F. Ormond, C. R. Clarke, and C. R. Voolstra. 2019. 'Similar bacterial communities on healthy and injured skin of black tip reef sharks', Anim Microbiome, 1: 9.

Sabirova, JS, M Ferrer, D Regenhardt, KN Timmis, and PN Golyshin. 2020. 'Proteomic Insights into Metabolic Adaptations in Alcanivorax borkumensis Induced by Alkane Utilization', Journal of Bacteriology, 188: 3763-73.

Schlame, M., S. Brody, and K. Y. Hostetler. 1993. 'Mitochondrial Cardiolipin in Diverse Eukaryotes Comparison of Biosynthetic Reactions and Molecular Acyl Species', European Journal of Biochemistry, 212: 727-35. 
Schmieder, R., and R. Edwards. 2011. 'Fast Identification and Removal of Sequence Contamination from Genomic and Metagenomic Datasets', Plos One, 6.

Shadwick, R.E. , A.P. Farrell, and C.J. Brauner. 2015. Physiology of Elasmobranch Fishes: Internal Processes (Academic Press).

Speers-Roesch, B, and JR Treberg. 2010. 'The unusual energy metabolism of elasmobranch fishes.', Comparative Biochemistry and Physiology Part A: Molecular \& Integrative Physiology, 155: 41734.

Sullivan, T., and F. Regan. 2011a. 'The characterization, replication and testing of dermal denticles of Scyliorhinus canicula for physical mechanisms of biofouling prevention', Bioinspiration \& Biomimetics, 6.

- - . 2011b. 'The characterization, replication and testing of dermal denticles of Scyliorhinus canicula for physical mechanisms of biofouling prevention', Bioinspiration \& Biomimetics, 6: 046001.

Tahon, G., L. Lebbe, M. De Troch, K. Sabbe, and A. Willems. 2020. 'Leeuwenhoekiella aestuarii sp. nov., isolated from salt-water sediment and first insights in the genomes of Leeuwenhoekiella species', Int J Syst Evol Microbiol, 70: 1706-19.

Tsutsui, S., Y. Dotsuta, A. Ono, M. Suzuki, H. Tateno, J. Hirabayashi, and O. Nakamura. 2014. ' A C-type lectin isolated from the skin of Japanese bullhead shark (Heterodontus japonicus) binds a remarkably broad range of sugars and induces blood coagulation.', Journal of Biochemistry, 157: 345-56.

Vendl, C., T. Nelson, B. Ferrari, T. Thomas, and T. Rogers. 2021. 'Highly abundant core taxa in the blow within and across captive bottlenose dolphins provide evidence for a temporally stable airway microbiota', BMC Microbiol, 21: 20.

Verma, H., G. G. Dhingra, M. Sharma, V. Gupta, R. K. Negi, Y. Singh, and R. Lal. 2020. 'Comparative genomics of Sphingopyxis spp. unravelled functional attributes', Genomics, 112: 1956-69.

Wen, L., P. J. M. Thornycroft, J. C. Weaver, and G. V. Lauder. 2015. 'Hydrodynamic function of biomimetic shark skin: effect of denticle pattern and spacing', Integrative and Comparative Biology, 55: E196-E96.

Williams, T. J., H. Ertan, L. Ting, and R. Cavicchioli. 2009. 'Carbon and nitrogen substrate utilization in the marine bacterium Sphingopyxis alaskensis strain RB2256', Isme Journal, 3: 1036-52.

Wilson, B., B. S. Danilowicz, and W. G. Meijer. 2008. 'The diversity of bacterial communities associated with Atlantic Cod Gadus morhua', Microbial Ecology, 55: 425-34.

Yang, L., X. H. Wang, S. Cui, Y. X. Ren, J. Yu, N. Chen, Q. Xiao, L. K. Guo, and R. H. Wang. 2019. 'Simultaneous removal of nitrogen and phosphorous by heterotrophic nitrification-aerobic denitrification of a metal resistant bacterium Pseudomonas putida strain NP5', Bioresour Technol, 285: 121360.

Zhang, D. Y., Y. Y. Li, X. Han, X. A. Li, and H. W. Chen. 2011. 'High-precision bio-replication of synthetic drag reduction shark skin', Chinese Science Bulletin, 56: 938-44.

Zheng, Q., W. X. Lin, Y. T. Liu, C. Chen, and N. Z. Jiao. 2016. 'A Comparison of 14 Erythrobacter Genomes Provides Insights into the Genomic Divergence and Scattered Distribution of Phototrophs', Frontiers in Microbiology, 7. 